\title{
Effects of Heat-Treatment on Tensile Behavior and Dimension Stability of 3D Printed Carbon Fiber Reinforced Composites
}

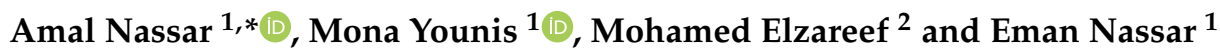 \\ 1 Mechanical Engineering Department, Higher Technological Institute, Next to Small Industries Complex, \\ Industrial Area 2, 10th of Ramadan City 11111, Egypt; Mona.Younis@hti.edu.eg (M.Y.); \\ eman.nasser@hti.edu.eg (E.N.) \\ 2 Mechanical Engineering Department, The British University in Egypt, Suez Desert Road, \\ El Sherouk City 11837, Egypt; mohamed.elzareef@bue.edu.eg \\ * Correspondence: Amal.nasser@hti.edu.eg
}

Citation: Nassar, A.; Younis, M.; Elzareef, M.; Nassar, E. Effects of Heat-Treatment on Tensile Behavior and Dimension Stability of 3D Printed Carbon Fiber Reinforced Composites. Polymers 2021, 13, 4305. https://doi.org/10.3390/ polym13244305

Academic Editors: Ahmed

Farouk Al-Hossainy, Shereen M.

S. Abdel-Hamid and

Mohamed Alkordi

Received: 11 November 2021

Accepted: 29 November 2021

Published: 9 December 2021

Publisher's Note: MDPI stays neutral with regard to jurisdictional claims in published maps and institutional affiliations.

Copyright: (C) 2021 by the authors. Licensee MDPI, Basel, Switzerland. This article is an open access article distributed under the terms and conditions of the Creative Commons Attribution (CC BY) license (https:// creativecommons.org/licenses/by/ $4.0 /)$

\begin{abstract}
This work investigated the effects of heat treatment on the tensile behavior of 3D-printed high modules carbon fiber-reinforced composites. The manufacturing of samples with different material combinations using polylactic acid (PLA) reinforced with $9 \%$ carbon fiber (PLACF), acrylonitrile butadiene styrene (ABS) reinforced with $9 \%$ carbon fiber (ABSCF) were made. This paper addresses the tensile behavior of different structured arrangements at different $\%$ of densities between two kinds of filaments. The comparison of the tensile behavior between heat treated and untreated samples. The results showed that heat treatment improves the tensile properties of samples by enhancing the bonding of filament layers and by reducing the porosity content. At all structure specifications, the rectilinear pattern gives higher strength of up to $33 \%$ compared with the Archimedean chords pattern. Moreover, there is a limited improvement in the tensile strength and modulus of elasticity values for the samples treated at low heat-treatment temperature. The suggested methodology to evaluate the tensile behavior of the pairs of materials selected is innovative and could be used to examine sandwich designs as an alternative to producing multi-material components using inexpensive materials.
\end{abstract}

Keywords: heat treatment; 3D printed; fiber-reinforced composites and tensile behavior

\section{Introduction}

Additive manufacturing (AM) is a new production technique, commonly called 3D printing, used for metal and polymer processing [1-3]. Products manufactured using AM are designed by adding material layer by layer, while products are built using subtractive manufacturing processes in traditional methods [4-6]. The cheap cost and adaptability in the construction of complicated designs have expanded the use of AM in current applications [7], such as development of products in the automotive industry, aerospace/biomedical applications, arts and design development, architecture, and so on $[1,2,8,9]$. Due to its growing use in the above stated applications, AM's development has grown strongly after 2013 [10]. Currently, aeronautical, electrical, and medicinal applications [11] are often employed in AM technology [12-14]. In addition to that, Tadesse et al. [15] use the three-dimensional (3D) printing to develop a flexible and lightweight electroluminescence (EL) device as a cost-effective technique for EL applications. AM is a flexible production technique that develops the product directly from the design file, decreasing the lead time for the product and material waste, and economically creates a complicated design [16]. Recently, many investments have been carried out to produce aircraft components by using AM, including brackets, panels, clips, and supports. Airbus used about 2700 components in A350 WXB aircraft made by using AM technology. Furthermore, South African company, Aerosud, has ordered more than 80 polymer components produced by AM technology for its aircraft to be used as air guidance ducts and low 
load-bearing air intakes. Using AM technology has reduced the cost and overall weight compared to using conventional metal parts [17].

However, there are a few problems in the AM process, such as, slow mass production and limited material use, which restrict it in several applications. AM has very selective material applications [18-20], since the additive manufactured materials are largely found only as a prototype model [21]. In this regard, the multiple printing head technique has been developed where composite materials can be created using controlled material combinations and properties [12]. The development of fiber composites is a more challenging approach for the AM process. Several aspects need to be considered for the development of fiber composites, including fiber weight percentage. Because of their excellent performance, manufacturing facility, and low cost, polymers are the materials most frequently utilized in various applications. In AM polymers, such reactive, fluid- and thermoplastic melts, are used in a range of different forms [22].

Industry has recently focused on the development of multilayered polymer materials and sandwich structure techniques for the Fused Deposition Modeling (FDM) process. Multilayer materials can improve the quality of 3D printing by optimizing the structure of various processes, allowing smart components to work $[16,18]$. Multi-material component manufacturing effectively increases mechanical properties, allows for new features, and improves AM process performance [23]. Furthermore, sandwich structure made from a mixture of polymer combinations, such as lightweight interior components for automobiles, has long been believed to be a suitable way to obtain a diversity of material properties for customized items. The outer skin of composite materials made of high-strength material sandwich the inner core of a lightweight material, which is covered with sandwich structures [21]. The inner core is usually made up of a wave structure because of its weight. However, problems, such as water ingress and delamination, may occur [24]. The necessary strength and stiffness would be attained by the difference between the skin material and the core, according to Daniel and Abot [25]. The optimum design for creating a lightweight composite appears to be more exact in the core material than in the thickness of the core layer, according to the findings of Herranen et al. [26]. For homogenous FDM thermoplastics, Lanzotti et al. examined the influence of process variables such as layer thickness, flow rate, deposition speed, feed rate, and build orientation on single PLA specimens [22,27]. Initially, it was found that all fibers must go down the loading line to maximize their Young's modulus and stiffness. On-line samples showed the best performance in terms of strength, stiffness, and ductility. Furthermore, increasing the layer's thickness and feeding rate reduces its ductility. Kuznetsov et al. [28] examined basic thickness and PLA infill density to enhance the form of FDM 3D-printed material, which can withstand larger stresses. The inclusion of certain volume features such as the fillet, roundness, and smooth contours to these process parameters has been found to enhance component strength more than twice that required to break the identical component while also reducing component mass considerably [29]. Fernandez-Vicente et al. [30] investigated the strength of different mesostructured ABS generated by the FDM technique to determine the optimum specimen, a tensile test was performed, which comprised material densities and infilling patterns. The best combination for greatest tensile strength was a rectilinear design with 100 percent infill density. To discover the best combination of ABS, PLA, and High impact polystyrene HIPS, researchers looked at a variety of materials. Mechanical testing was carried out by Singh et al. and Kumar et al. [31,32]. The three materials were printed using the twin extrusion (TSE) technique as a stack of different multi-layers in the same shape. Saad [33] created an ABS and PLA sandwich structure to test the diversity of their mechanical and physical properties. Various percentages of honeycomb pumps were used in the study to test and validate the weight benefit of pore size volumes on mechanical properties. The results of tensile and bending tests showed that if the infill density increases while the steadiness remains constant as the bending force increases, the tensile strength increases. Furthermore, 3- and 4-point ABS and PLA sandwich bending tests were recommended by Brischetto et al. [34]. Infill patterns such as the core layers (honeycomb and homogenous) 
and the number of extractors employed to make specimens have an impact. The modulus of elasticity of ABS and PLA honeycomb core, in particular, was impacted by all of these variables. In order to improve their mechanical performance, Santosh et al. [35] utilized layered structures using ABS and PLA.

Heat treatment of polymer materials made by perfecting the interfacial bonding to improve the mechanical properties [36,37]. However, the studies of the effect of heat-treatment on 3D-printed composites remain limited. MacDonald et al. [38] found that porosity and mechanical properties are affected by heat treatment of the polyether ether ketone produced by ASTM 52900 process. Nabipour et al. [39] studied the relationship between annealing and increasing tensile strength of (PLA) 3D-printed samples. They noticed that heat-treatment can improve the interface bonding which leads to an increase in the density. Wang et al. suggested that the heat treatment process can improve the tensile strength of poly wax 3D-printed samples by reducing the amount of porosity. Some researchers studied the tensile behavior of 3D-printed PLA reinforced by short carbon fiber SCF after heat treatment process [40]. Natalia et al. [41] studied the influence of porosity, crystallinity, and interlayer adhesion on the tensile strength of 3D-printed polylactic acid (PLA). Their final results prove that medical diameter and layer height are the most significant factors that affect the mechanical properties of 3D-printed parts. Similar results were postulated by Travieso-Rodriguez et al. [42]. Afonso [43] et al. studied the influences of the fused filament fabrication parameters process on the mechanical properties for printed polylactic acid (PLA) parts. They found that the greatest influence parameter in the fabrication process is the extrusion temperature. Gardner et al. [44] proved that the annealing process enhanced the tensile properties of 3D-printed composites reinforced with SCF. Thus, it can be concluded that an annealing process can affect the porosity, interface bonding, and crystallinity of polymer for 3D-printed composites. Nevertheless, the synergistic effects of the annealing process on the mechanical behavior and microstructure require more study. Although, as per the authors' knowledge, no research has focused on the relevance of heat-treatment, matrix type, and infill density and pattern. This work investigates the effect of using heat treatment as a solution to the poor mechanical properties of 3D-printing products. The novel structure of the sandwich is suggested here, with specimens incorporating rectilinear cores and Archimedes with an infill density of 100 percent and 70 percent for each material inside a single carriage and employing many independent nozzles extruders. In this novel scheme, the effect of combining traditional (ABSCF and PLACF) materials as a sandwich structure for achieving and improving the greater strength of polymer elements that may be employed in diverse applications, could be compared.

\section{Experimental Work}

\subsection{Materials}

The test materials are acrylonitrile butadiene styrene with $9 \%$ concentration of carbon fibers (ABSCF) (CarbonX ${ }^{\mathrm{TM}}$, 3DXTECH, Grand Rapids, MI, USA) and polylactide with 9\%concentration of carbon fibers (PLACF) (CarbonX ${ }^{\mathrm{TM}}$, 3DXTECH, Grand Rapids, MI, USA). The properties of both filaments according to the $3 \mathrm{dxtech}$ data sheet are shown in Table $1[45,46]$. In FDM, the polymers are extruded and mounted in a product development layer by layer technique. FDM produced polymers show adequate mechanical performance, high surface quality, and reliability at reasonable prices compared to other AM techniques. The FDM method material is in the form of long wires or filament wound on as pool.

Table 1. Properties of polymer ABSCF and PLACF.

\begin{tabular}{cccccccc}
\hline $\begin{array}{c}\text { Filament } \\
\text { Type }\end{array}$ & $\begin{array}{c}\text { Density } \\
\text { g/cc }\end{array}$ & $\begin{array}{c}\text { Tensile } \\
\text { Strength } \\
\mathbf{( M P a )}\end{array}$ & $\begin{array}{c}\text { Tensile } \\
\text { Modulus } \\
\mathbf{( M P a )}\end{array}$ & $\begin{array}{c}\text { Tensile } \\
\text { Elongation } \\
\mathbf{( \% )}\end{array}$ & $\begin{array}{c}\text { Flexural } \\
\text { Strength } \\
\mathbf{( M P a )}\end{array}$ & $\begin{array}{c}\text { Extrusion } \\
\text { Temp }\end{array}$ & $\begin{array}{c}\text { Glass } \\
\text { Transition } \\
\text { Temperature }\end{array}$ \\
\hline PLACF & 1.29 & 48 & 4950 & 2 & 89 & $215^{\circ} \mathrm{C}$ & $60{ }^{\circ} \mathrm{C}$ \\
ABSCF & 1.11 & 46 & 5210 & 2 & 76 & $230{ }^{\circ} \mathrm{C}$ & $105^{\circ} \mathrm{C}$ \\
\hline
\end{tabular}


Firstly, specimens were printed as a single homogeneous material with fixed parameters to be compared with the multi-material specimens. Secondly, the combination of materials for the sandwich structure was performed with four-layer sections of each material. It contained symmetrical 1.2-mm-thick polymeric inner and outer cores (four layers of $0.3 \mathrm{~mm}$ thick per material) giving a total dimension of a $3.6 \mathrm{~mm}$ thick specimen in accordance with the dimensions of the standard test method for tensile properties of plastics as shown in Figure 1. All specimens were printed in a flat direction on the XY plane with a rectilinear pattern, stacking sequence of $45^{\circ} / 45^{\circ}$, and vertically upward layer by layer within the $\mathrm{Z}$ direction. The air gap was recognized as zero (beads just touch). Sample configurations are:

- Type (A) for ABSCF: ABSCF 100/rectilinear; ABSCF 70/rectilinear; ABSCF 100/Archim edean chords; ABS 70/Archimedean chords,

- $\quad$ Type (A) for PLACF: PLACF 100/rectilinear; PLACF 70/rectilinear; PLACF 100/Archim edean chords; PLA 70/Archimedean chords,

- Type (B) for PLACF-ABSCF-PLACF: PLACF-ABSCF-PLACF 100/rectilinear; PLA-ABSCFPLACF 70/rectilinear; PLACF-ABSCF-PLACF 100/Archimedean chords; PLACF-ABSCFPLACF 70/Archimedean chords,

- Type (B) for ABSCF-PLACF-ABSCF: ABSCF-PLACF-ABSCF 100/rectilinear; ABSCFPLACF-ABSCF 70/rectilinear; ABCFS-PLACF-ABSCF 100/Archimedean chords; ABSCFPLACF-ABSCF 70/Archimedean chords,

- Type (B) for PLACF-ABSCF-PLACF: PLACF-ABSCF-PLACF 100/rectilinear; PLACFABSCF-PLACF 70/rectilinear; PLACF-ABSCF-PLACF 100/Archimedean chords; PLACFABSCF-PLACF 70/Archimedean chords.

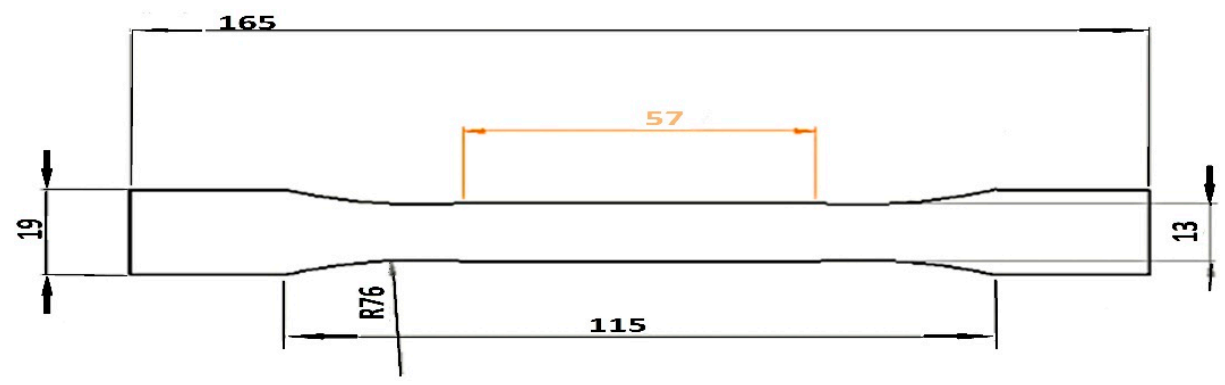

Figure 1. Dimension details of the tensile test sample according to ASTM D638.

The samples were divided into two groups. The first group was subjected to heat treatment and the other group was examined without any treatment.

\subsection{Printing Process}

Printing process of the selected type of composite filaments made by using a single head. In the printing process, multiple layers are used to produce the required sample (Figure 2). The FDM printing used is done by a 3D printer of type original Prusa MK3S (Prusa company, Prague, Czech Republic), according to layer distributions and infill patterns in Figure A1. The method proposes a sandwich structure with a total thickness of $3.6 \mathrm{~mm}$, The two outer skins have a global thickness of $2.4 \mathrm{~mm}$ and the inner core a thickness of $1.2 \mathrm{~mm}$ made of a PLACF or ABSCF with a rectilinear or Archimedean chords infill pattern and $100 \%$ or $70 \%$ density, the speed rate was in accordance with the loading rate used in previous studies $[22,27,29,30]$. Table 2 shows parameters of the printing for each filament type. Table 3 illustrates the given code for each sample. 


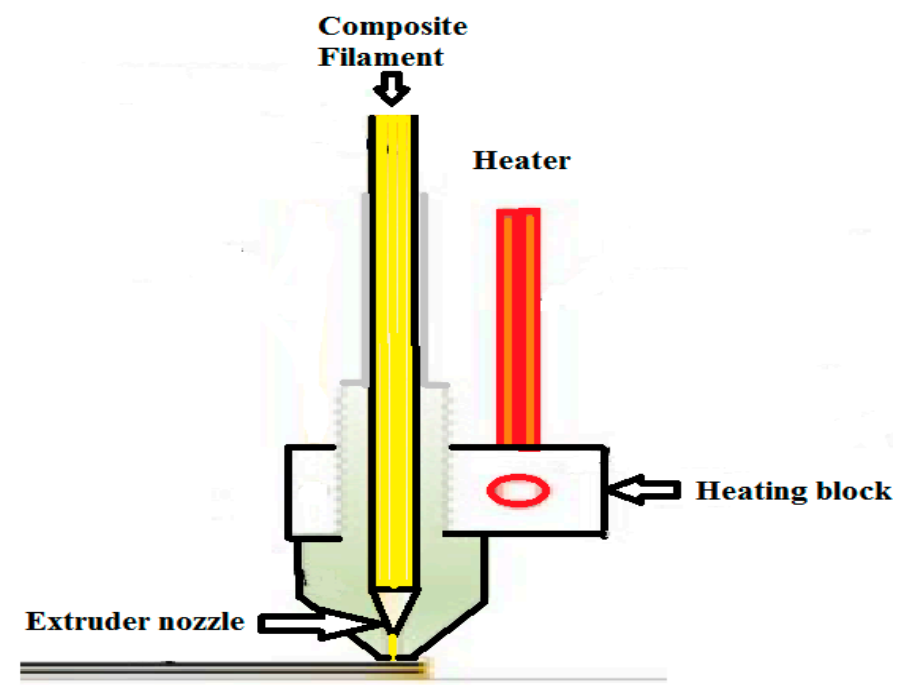

Figure 2. Schematic of using single head in manufacturing process.

Table 2. Printing parameters.

\begin{tabular}{|c|c|c|c|c|}
\hline Infill Pattern & Density \% & $\begin{array}{c}\text { Feed Rate } \\
\left(\mathrm{E} / \mathrm{mm} \mathrm{min} \mathrm{min}^{-1}\right)\end{array}$ & $\begin{array}{l}\text { Printing Speed } \\
\left(\mathrm{E} / \mathrm{mm} \min ^{-1}\right)\end{array}$ & Bed Temp. ${ }^{\circ} \mathrm{C}$ \\
\hline Rectilinear & $100 / 70$ & 80 & 100 & PLACF: $23^{\circ} \mathrm{C}$ \\
\hline $\begin{array}{l}\text { Archimedean } \\
\text { chords }\end{array}$ & $100 / 70$ & 80 & 100 & ABSCF: $110^{\circ} \mathrm{C}$ \\
\hline
\end{tabular}

Table 3. Sample codes.

\begin{tabular}{cccc}
\hline Material & Infill Pattern & Density & Code \\
\hline ABSCF-PLACF-ABSCF & Rectilinear & 100 & SA11 \\
ABSCF-PLACF-ABSCF & Rectilinear & 70 & SA17 \\
ABSCF-PLACF-ABSCF & Archimedean chords & 100 & SA21 \\
ABSCF-PLACF-ABSCF & Archimedean chords & 70 & SA27 \\
PLACF-ABSCF-PLACF & Rectilinear & 100 & SP11 \\
PLACF-ABSCF-PLACF & Rectilinear & 70 & SP17 \\
PLACF-ABSCF-PLACF & Archimedean chords & 100 & SP21 \\
PLACF-ABSCF-PLACF & Archimedean chords & 70 & SP27 \\
ABSCF & Rectilinear & 100 & PA11 \\
ABSCF & Rectilinear & 70 & PA17 \\
ABSCF & Archimedean chords & 100 & PA21 \\
ABSCF & Archimedean chords & 70 & PA27 \\
PLACF & Rectilinear & 100 & PP11 \\
PLACF & Rectilinear & 70 & PP17 \\
PLACF & Archimedean chords & 100 & PP21 \\
PLACF & Archimedean chords & 70 & PP27 \\
\hline
\end{tabular}

\subsection{Heat Treatment}

Annealing or heat-treatment experiments were established to analyze the deformation caused by the annealing process in the dimensions length $(\mathrm{L})$ and thickness $(\mathrm{T})$ of the specimen as shown in Figure A2.

The annealing process is done by first putting the specimens in a ceramic container and leaving around two inches of space around it on all sides. The powder used in the annealing process is a mixture of sodium chloride powder (table salt), potassium iodate $50 \mathrm{mg} / \mathrm{kg}$, and E536 anti-caking agent. These are non-toxic, inexpensive materials, and high-temperature resistant, used to distribute the heat uniformly around the specimen and 
prevent deformation of the parts. The powders were mixed and ground into small particles (about $50 \mu \mathrm{m}$ ) and then heated to $200{ }^{\circ} \mathrm{C}$ for $40 \mathrm{~min}$ to remove moisture, then it was left to cool down in a sealed container. The resulting powder is added to the bottom of the container and then the specimens are placed on top of it as shown in Figure A3, then the sodium chloride powder is gently poured all around them. The electrical heater oven is pre-heated and left until it holds temperature for $10 \mathrm{~min}$ and then the container is inserted inside the oven and left for $20 \mathrm{~min}$ to make sure the salt has enough time to fully heat up and transfer that heat to the specimens.

A thermometer is inserted into the salt to make sure the internal temperature is the same as what the oven thermometer reads. The container with samples is left inside the oven for $10 \mathrm{~min}$ at the set temperature. After that, the container is left to cool down at room temperature $\left(25^{\circ} \mathrm{C}\right)$. This process is done at three different temperatures which are $50^{\circ} \mathrm{C}$, $120{ }^{\circ} \mathrm{C}$, and $150{ }^{\circ} \mathrm{C}$ for all the sandwich specimens; these values are set in order to be above the glass transition temperature and below the melting point of the material used in the specimens, so for the sandwich specimens, an average value of the two materials is taken. Specimens' thicknesses and widths, before and after annealing, were measured using a digital Vernier caliper to analyze the deformation that happened.

\subsection{Characterization}

The effect of heat-treatment over type A and type B samples with different kinds of filaments were studied. This study includes physical experiments and mechanical tests for the samples. The physical experiments include porosity and dimension measurements, and mechanical tests include tensile tests. The changes in the dimension under the effect of heat treatment was measured by using a digital Vernier caliper and the results were the average of 3 readings. The density measurement was used to calculate the porosity $\%$ by using Formula (1).

$$
\text { Porosity } \%=(\{\mathrm{D} \text { (filament type })-\mathrm{D}(\text { Printed sample })\} / \mathrm{D}(\text { filament })) \times 100
$$

In this formula, the densimeter type (DH-300K DahoMeter digital electronic, Dongguan Hong Tuo Instrument Co., Dongguan, China) based on the standard D 792-07 was used to measure the density of filament type (ABSCF, PLACF) and the density of the printed sample; the value of each sample was recorded as an average of three readings.

\section{Results and Discussion}

\subsection{Stability of the Dimension}

Figure 3 shows the internal structure of the sample with density infill $70 \%$ and $100 \%$, the large distance between filaments in the case of $70 \%$ infill density and the proximity between the filaments in case of infill $100 \%$ is clear from the figures. Figures 4 and 5 show relative change values of width (L) and thickness (T) for the composites under different heat-treatment conditions, respectively. It was found that increasing the temperature of heat treatment up to $150{ }^{\circ} \mathrm{C}$ leads to a decrease in the width and thickness in all samples. For example, the percentage dimensional change of ABSCF-PLACF-ABSCF/rectilinear pattern $/ 100$ was $0.19 \%$ at $50{ }^{\circ} \mathrm{C}$ and 0.68 at $150{ }^{\circ} \mathrm{C}$. In addition to that, the density of infill was an important parameter in the \% of relative change value of the sample width and thickness. With the decrease of infill density up to $70 \%$, the width and thickness of the sample tend to decrease. The maximum change in dimension was $19.46 \%$ found in PLACF/rectilinear/100 with thickness after $150{ }^{\circ} \mathrm{C}$ heat-treatment. The results also revealed that the pattern shape was an important parameter in the \% of relative change value of the sample width and thickness. Samples with Archimedean chords pattern shape showed lower \% of relative change value of the sample width and thickness compared with samples with rectilinear pattern. For example, the \% dimensional change of ABSCF/Archimedean chords $/ 100$ was $11.07 \%$ while the $\%$ dimensional change of the rectilinear pattern was 8.02 at the same heat treatment temperature. 
Large spacing in between filaments

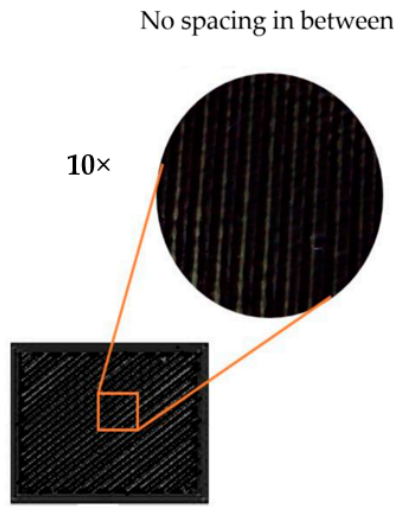

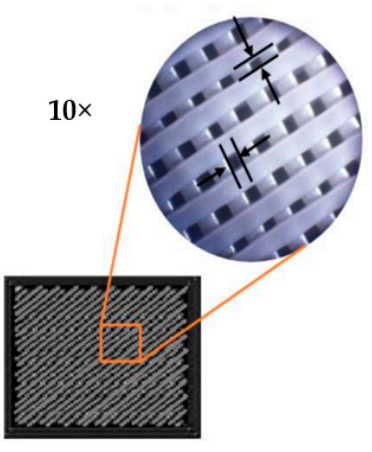

b

Figure 3. Internal structure of (a) density infill 70\%, (b) density infill 100\%.

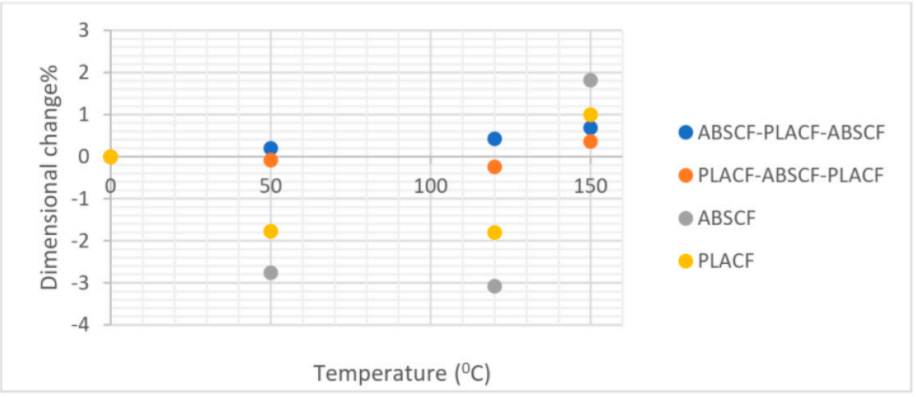

$\Delta \mathrm{L}$ of Rectilinear at density $100 \%$

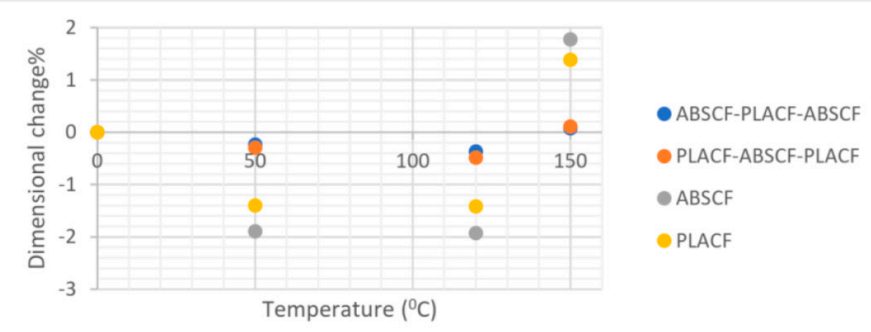

$\Delta \mathrm{L}$ of Rectilinear at density $70 \%$

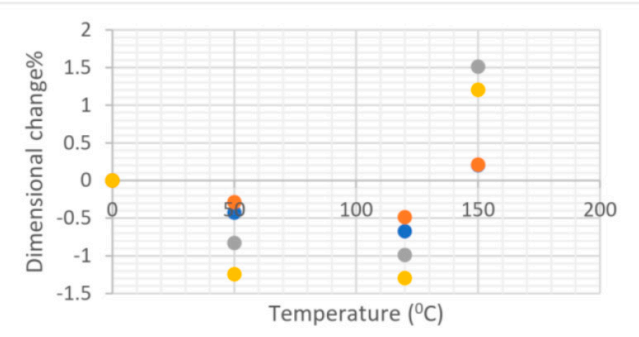

- ABSCF-PLACF-ABSCF

- PLACF-ABSCF-PLACF

- ABSCF

- PLACF

$\Delta \mathrm{L}$ of Archimedean chords at density $100 \%$

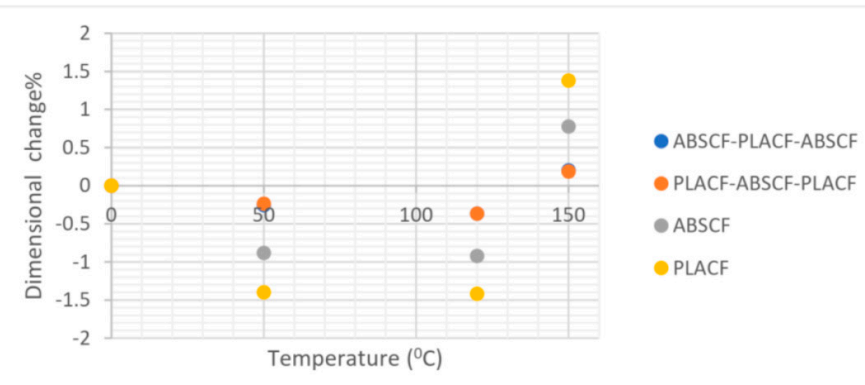

$\Delta \mathrm{L}$ of Archimedean chords at density $70 \%$

Figure 4. Relative change values of width (L) for the samples under different heat-treatment conditions. 


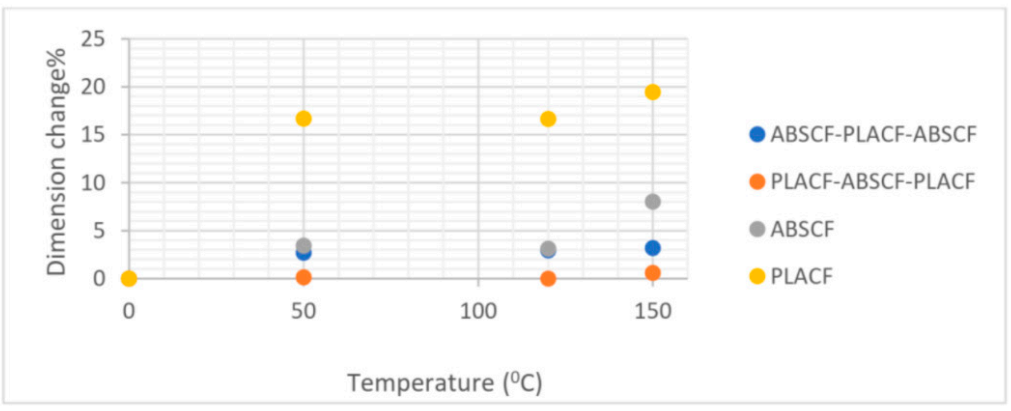

$\Delta \mathrm{T}$ of Rectilinear at density $100 \%$
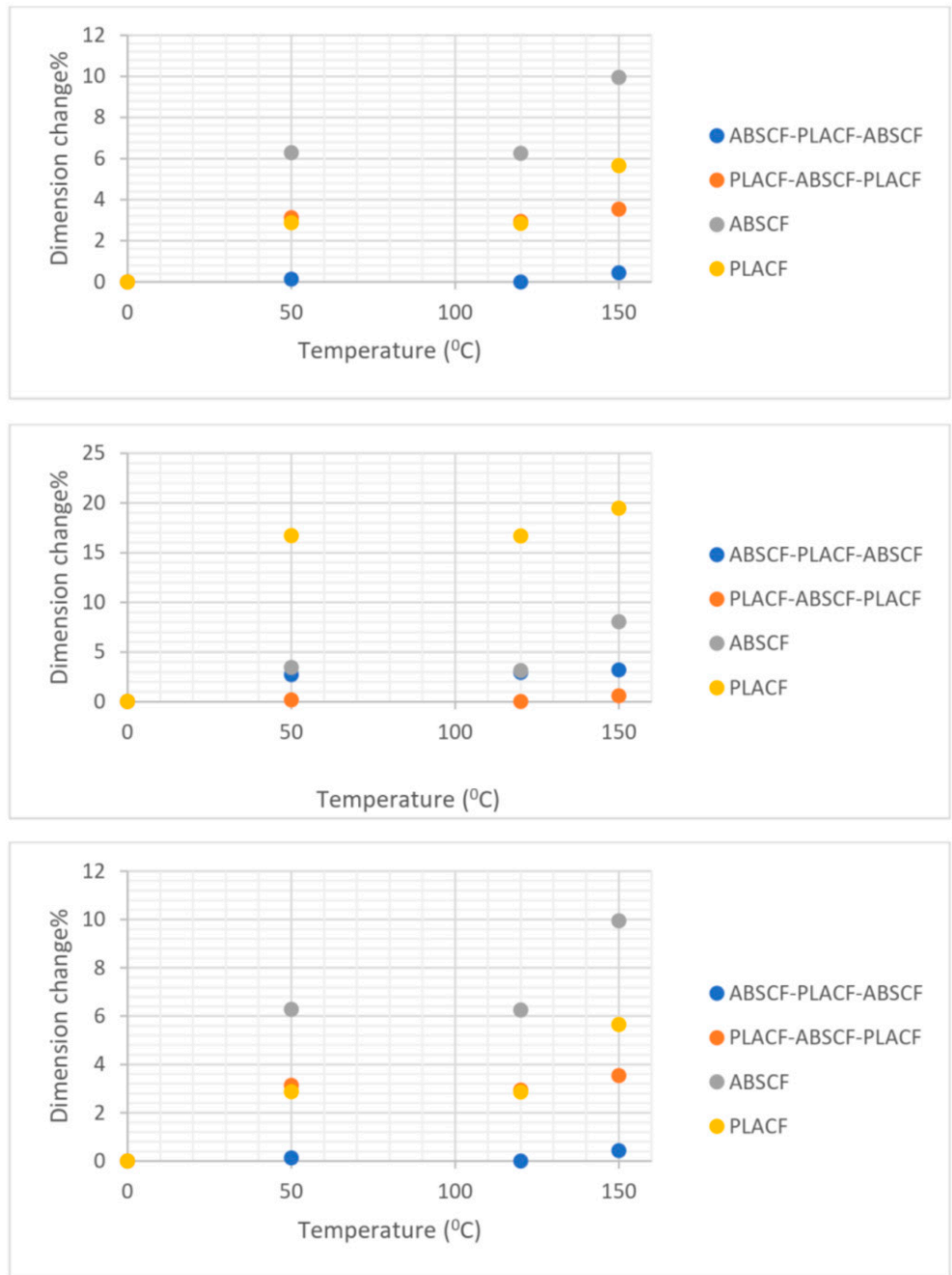

$\Delta \mathrm{T}$ of Rectilinear at density $70 \%$

$\Delta \mathrm{T}$ of Archimedean chords at density $100 \%$

$\Delta \mathrm{T}$ of Archimedean chords at density $70 \%$

Figure 5. Relative change values of thickness $(\mathrm{T})$ for the samples under different heat-treatment conditions.

\subsection{Mechanical Properties}

3.2.1. Tensile Strength

Figures A4 and A5 represent the results of tensile strength testing for samples of types A and B. It is clear from the figures that heat-treated samples had a remarkable increase in stiffness and strength compared with the non-treated samples. The maximum tensile strength for heat treatment samples was 257.4 MPa for sample PP1 1 at $150{ }^{\circ} \mathrm{C}$ and the minimum tensile strength was $15.02 \mathrm{MPa}$ obtained for sample PA21 treated at $50{ }^{\circ} \mathrm{C}$. Heat treatment at $150^{\circ} \mathrm{C}$ shows a remarkable increase in the tensile strength; at this temperature, samples exhibited $155.24 \%$ increased strength over the untreated samples in the case of 
ABSCF-PLACF-ABSCF with 100\% rectilinear infill. This was due to a delay in the crack initiation for the heat-treated samples under the effect of decreasing porosity at filament layers, which led to increasing the sample strength [3]. In addition to enhancement of tensile strength, samples treated at $150^{\circ} \mathrm{C}$ show an increase in Young's modulus of elasticity; at this temperature, the samples displayed $12.5 \%$ increase in Young's modulus of elasticity over the untreated samples in the case of PLACF-ABSCF-PLACF with 100\% Archimedean chords infill. The results also reveal that there is a significant correlation between the heat treatment temperature and tensile properties. This is due to the limited improvement in the tensile strength and modulus of elasticity values for the samples treated at low heat-treatment temperature compared with samples treated at high temperatures. On the other hand, the maximum tensile strength for untreated samples was 151.7 MPa at sample PP21 and the minimum tensile strength was $54.39 \mathrm{MPa}$ obtained in the SA27 sample.

\subsubsection{Porosity Measurement}

Figure 6 shows the effect of heat treatment on the porosity \% of different samples, it illustrates the values of porosity $\%$ at different heat treatment temperatures. It is clear from the bars values that the porosity decreases with the increase of heat treatment temperature. For example, the porosity $\%$ of sample SA11 was $9.28 \%$ at $50{ }^{\circ} \mathrm{C}$ and 8.03 at $150{ }^{\circ} \mathrm{C}$. In addition to that, the density of infill was an important parameter in the porosity $\%$. With the decrease of infill density up to $70 \%$, the porosity $\%$ tended to increase. Furthermore, the pattern of the filament has a significant effect on the porosity \%; rectilinear pattern shows lower porosity \% compared with the Archimedean chords pattern. For example, the porosity \% of sample PA27 was $9.12 \%$ and $9.31 \%$ for PA21. In addition, samples with the same filament type show lower porosity \% compared with the samples with different filament types. The minimum value of porosity \% was $8.03 \%$ for sample SA11 treated at $150{ }^{\circ} \mathrm{C}$ and the maximum value of porosity $\%$ was $9.88 \%$ obtained in untreated sample SA27. The previous results agree with the microscopic images of the cross-section of the samples at the different temperatures for heat treatment in Figure 7. Microscopic image analysis reveals that internal voids were reduced with the further decrease in heat treatment temperature. In other words, when the sample is treated at a temperature near to the glass transition of polymer, the motion of the molecule becomes sufficient to fill voids and to enhance interlayer fusion.

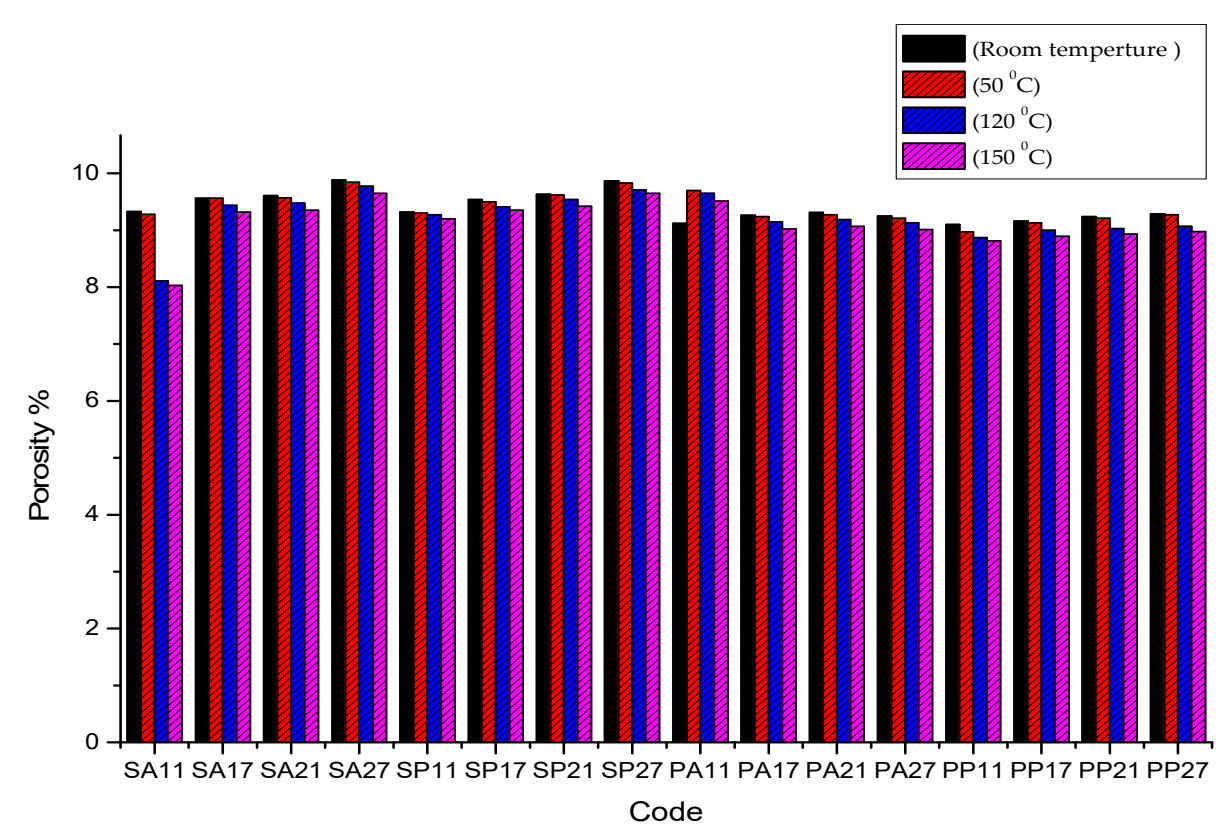

Figure 6. variation of the porosity \% with the changing in the heat treatment temperature. 

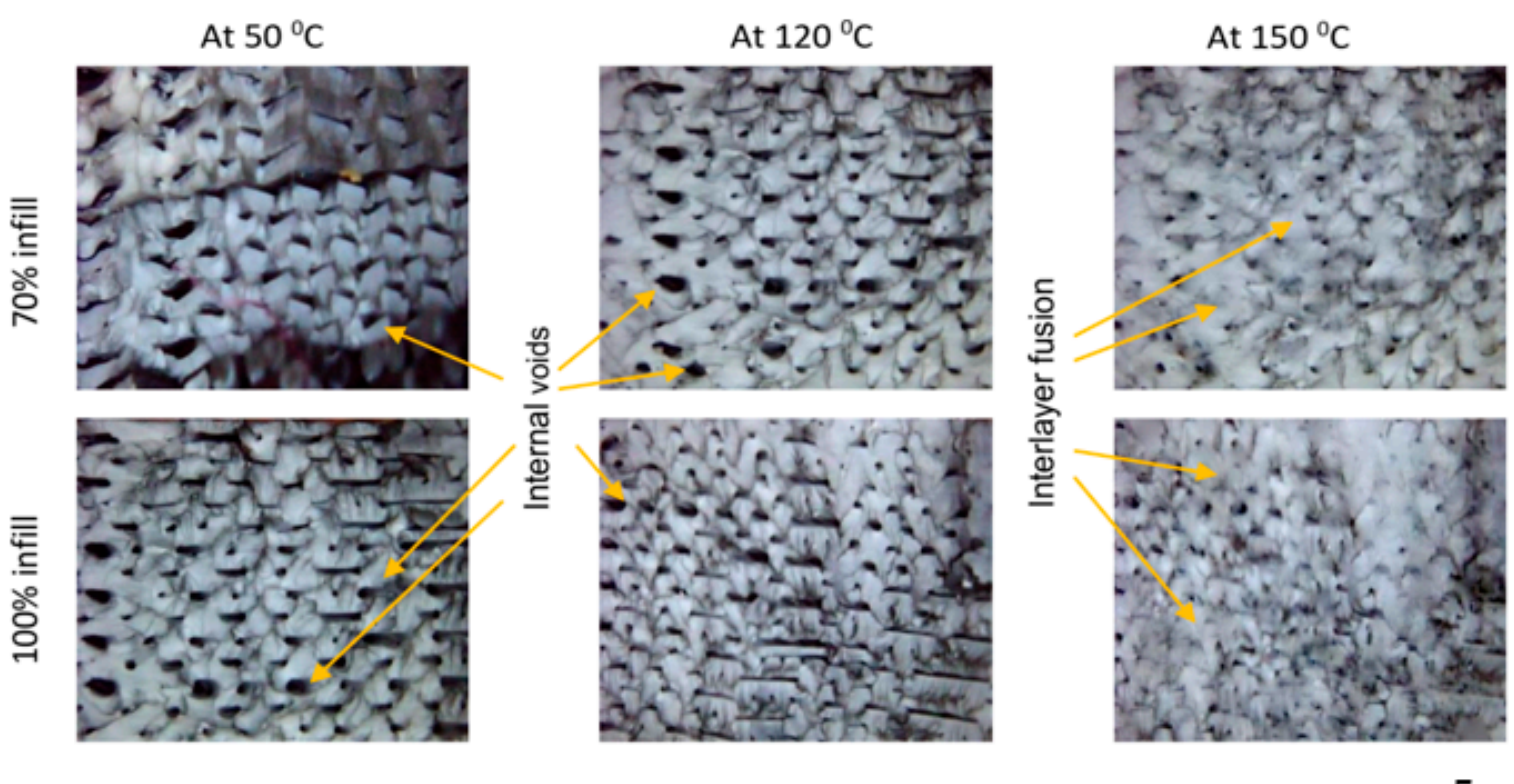

$5 \times$

Figure 7. Microscopic images of the cross-section of the samples at different temperatures for heat treatment.

\subsection{SEM Analysis}

In order to study the effect of heat-treatment on the failure response of samples, scanning electron microscope (SEM) was used to fracture surfaces of tensile test samples. Six samples were chosen according to the best and worst tensile behavior given by them. These samples are PP11 as the best ultimate strength for unannealed specimens andPP11-A the best strength for annealed specimens. The highest elasticity specimens which are SA21 for unannealed specimens and SA11-A for annealed specimens. The worst strength is the SA27 and the lowest elasticity is SP17-A. The scanning was performed twice for each specimen at magnifications of 50 and 200.

Figure 8 shows the SEM images for the PP11 specimen (PLACF with $100 \%$ rectilinear infill) which gives the highest ultimate strength among all the other unannealed specimens. Here the pure rectilinear PLACF shows flake structure at the outer layers and complete merger between filaments due to complete fusion in the filament interlayer; while the overall crosslinking is strong which gives high ultimate strength value. On the other hand, annealed PP11 gives the highest ultimate strength among all the other annealed specimens with ultimate strength equal to $46 \mathrm{MPa}$. By comparing those specimens, it is noticeable that the filament material becomes more fusional in the annealed samples than unannealed samples, which makes excellent interfacial contact between layers. In other words, heat treatment reheats the filament which improves the crosslinking between filament surfaces compared with the crosslinking of filament in the same sample without an annealing process.

Figure 9 shows the SEM of the SA21 (PLACF-ABSCF-PLACF with 100\% Archimedean chords infill) which gives the highest Young's modulus among all the other unannealed specimens $(1.49 \mathrm{GPa})$. The material here is ductile as seen in the fracture surface, this is due to appearance of the transition region with hackles and mists [42]. Meanwhile, the surface of fracture for the heat treatment sample SA11 shows shiny and smooth surface which refers to fusion or remelting of the outer surface of the filament material. Furthermore, the surface of the fracture failure after heat treatment was brittle due to the plastic deformation in the filament material under the temperature of heat treatment. Figure 10 shows the SEM of the SA27 (ABSCF-PLACF-ABSCF with 70\% Archimedean chords infill) which gives the lowest ultimate strength among all the other annealed and unannealed specimens. Here the sandwich specimen, which has an ABSCF outer layer, exhibits the lowest tensile strength as it has a lot of voids and poor crosslinking between filament surfaces. The SEM images 
reveal the appearance of voids in the filament layer of ABSCF and filament layer of PLACF due to fusion temperature deference between them. However, interfacial contact appears between the same types of filaments, due to same thermal properties. Figure 11 shows the SEM photos of SP17 (PLACF-ABSCF-PLACF with 70\% rectilinear infill) which gives the lowest Young's modulus among all the other annealed and unannealed specimens. This behavior is due to the bad bonding between dissimilar materials of the filaments. It is clear from the SEM image that the interfacial contact or the adhesion appears only between the same type of filament. On the other hand, bad tensile properties of the sandwich from different types of filaments have resulted from the mismatched strain between the layers.
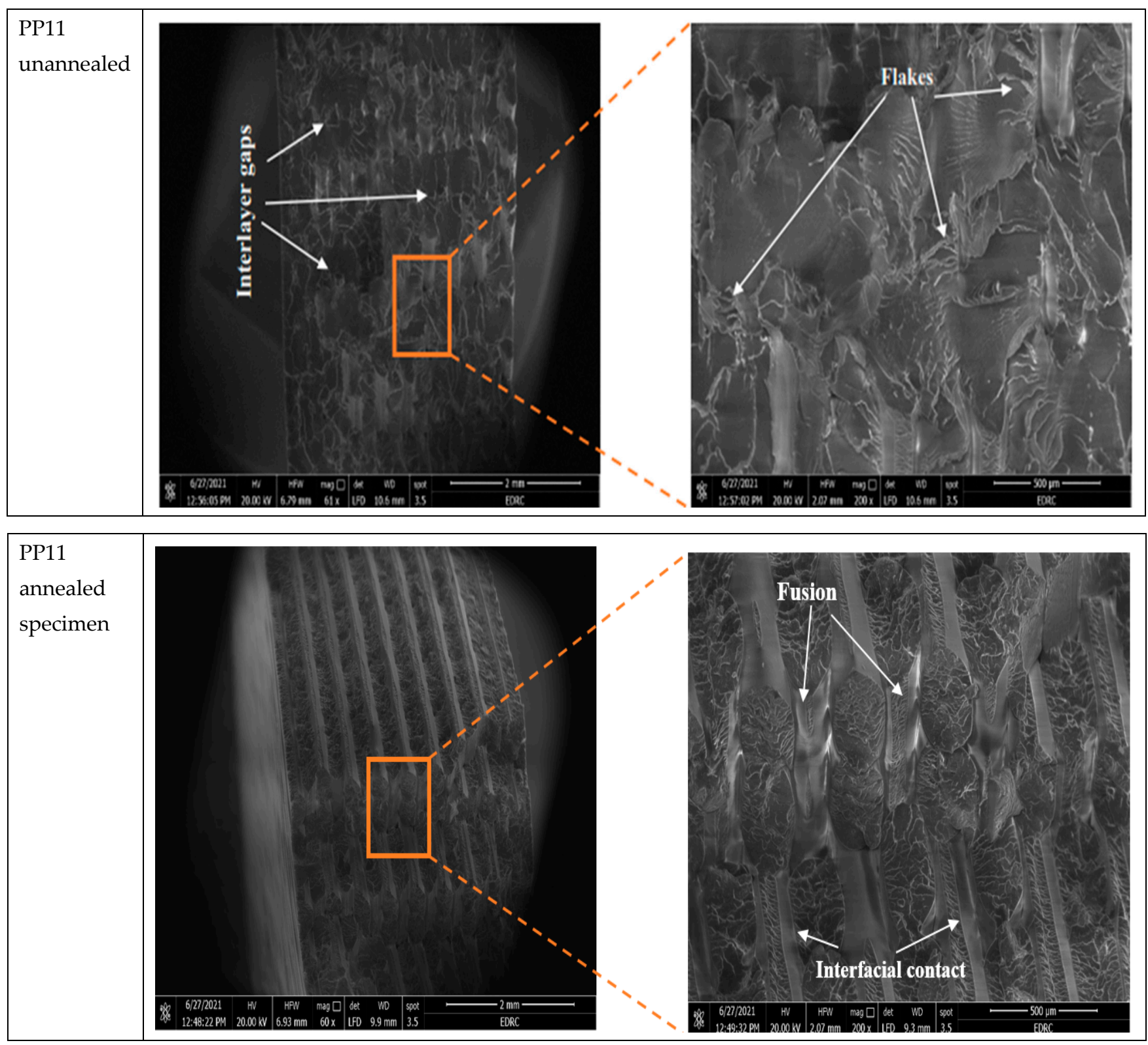

Figure 8. SEM photos and EDS plot of the effect of heat treatment over PP11 sample. 

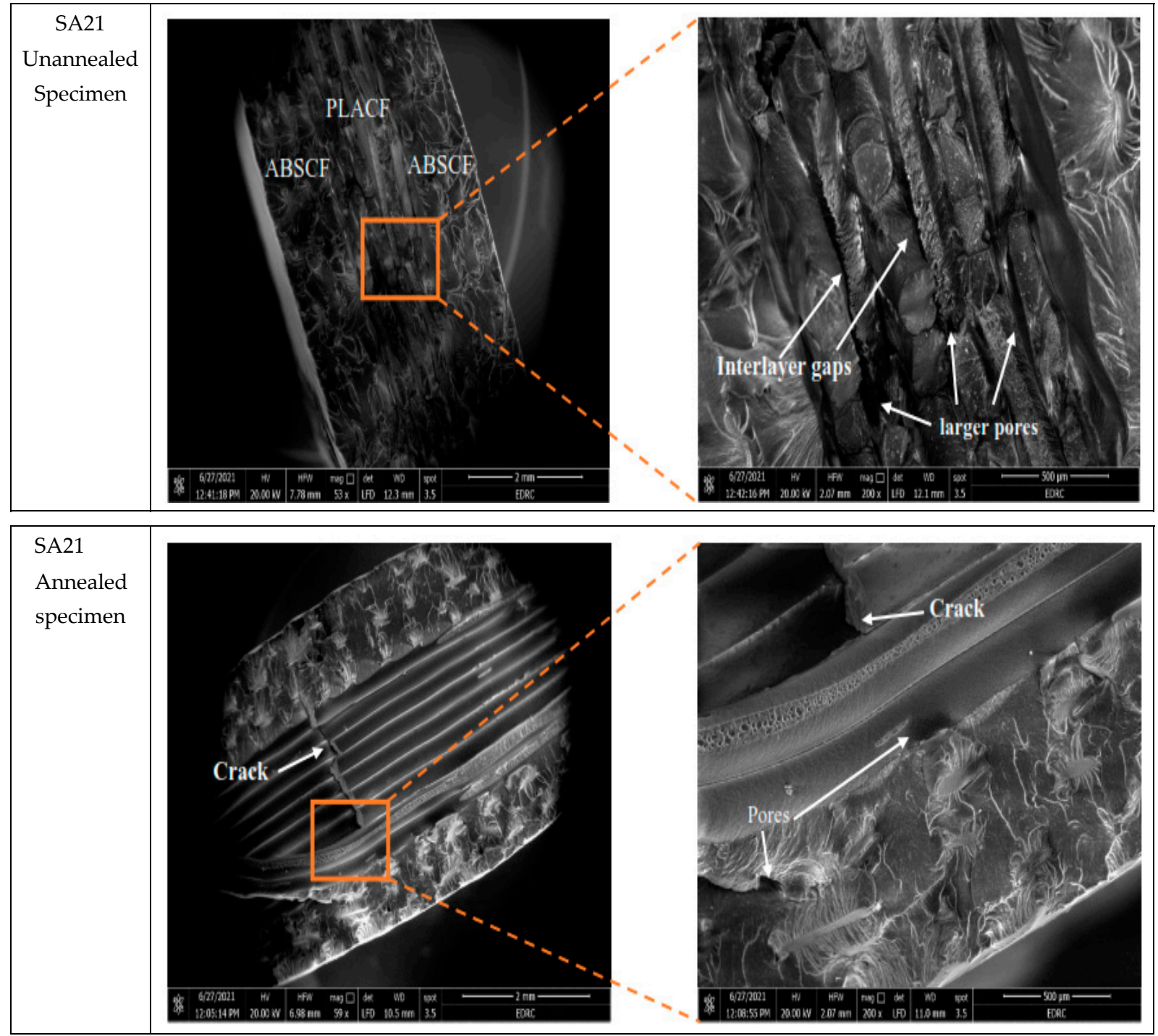

Figure 9. SEM photos for the effect of heat treatment over SA21sample.

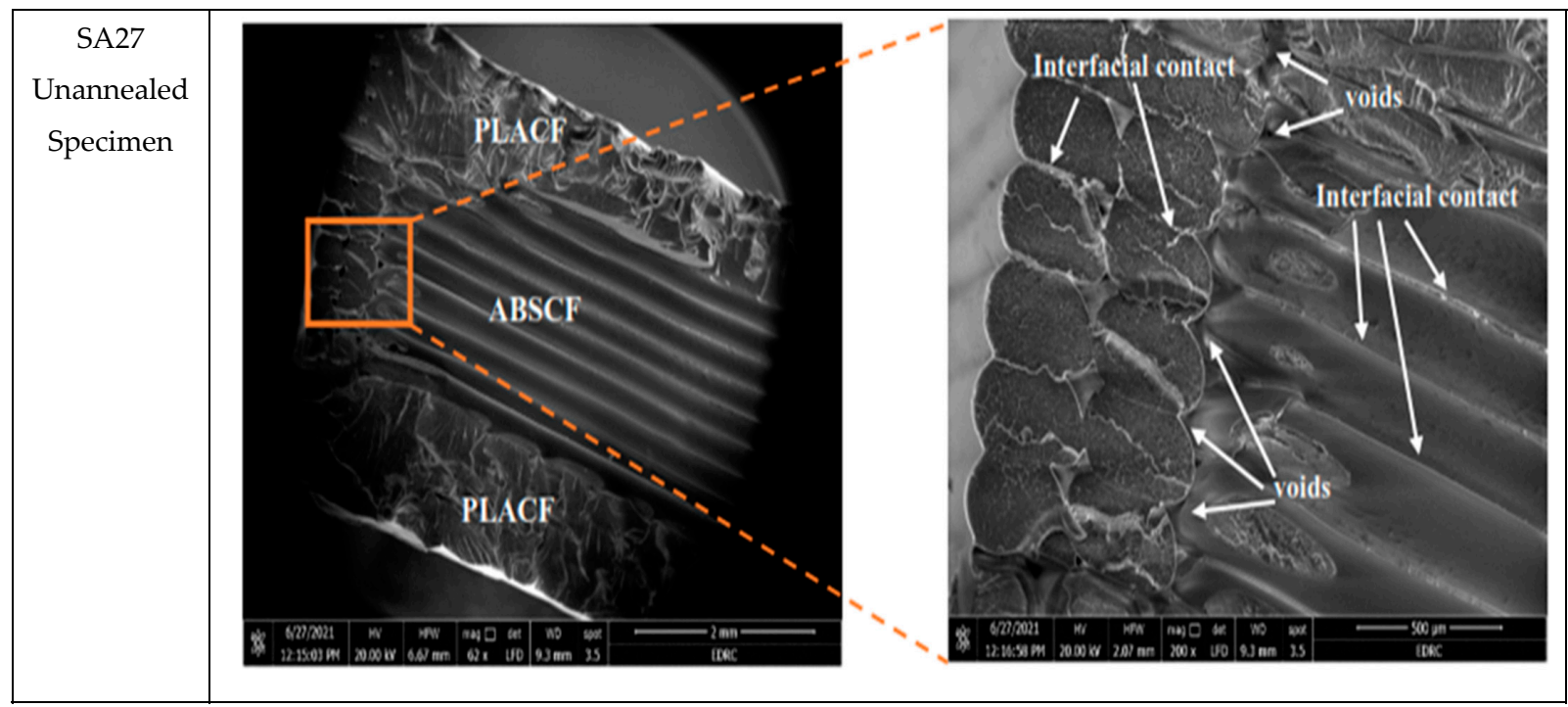

Figure 10. SEM photos of unannealed SA27specimen. 


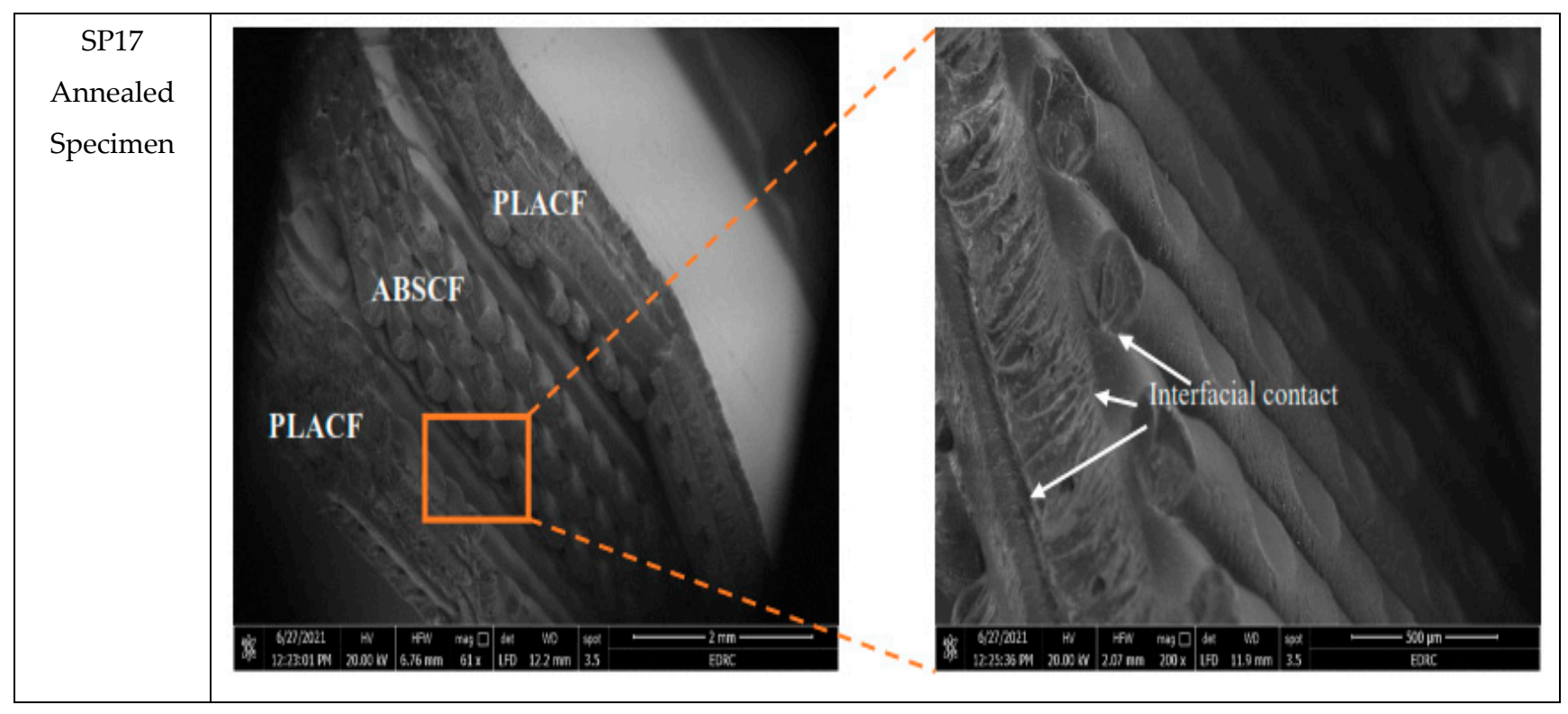

Figure 11. SEM photos for the effect of heat treatment over SP17sample.

\section{General Comments}

This paper analyses the effect of heat treatment at three different temperatures on the physical and tensile behavior of two types of filaments printed by using two infill densities and two patterns infill. The percentages of porosities shown correlated with densities and patterns of infill; this is due to differences in thermal expansion of the filament which affects interfacial bonding between filament layers, the other reason for the porosity is the lack in filling to complete the geometric space between filaments in case of the small density $(70 \%)$ [43]. It is clear from Figure 3 that there is a large space between the filaments in the case of density infill $70 \%$, while the filaments are very close to each other in the case of density infill $100 \%$.

The rectilinear pattern shows lower porosity compared with the Archimedean chords pattern as a result of the design of its structure which consists of square prismatic channels separated by perpendicular walls and parallel walls. This structure provides low spacing between filament interfacials which reduces the possibility of pores creation, the same observation was found by Keles [44]. The most critical porosity due to intra bead pores can be eliminated by enhancing the adhesion between fiber and matrix and using high-quality filaments [45].

Reduction in the tendency of porosity for printed samples after the heat treatment process is returned to shrinkage and creeping in the polymer interfacial [46-48]. Although selecting a suitable heat treatment temperature is essential in the improvement of mechanical properties [49], if the heat treatment temperature is less than the melting temperature of the filament, the porosity will remain as it is without any changes. Thus, the mechanical properties will not improve. Moreover, the main affected parameter with the heat treatment is the crystallization temperature of the filament, therefore the changes in porosity will occur only if there is a change in filament crystallinity after the heat-treatment process [50,51]. This increase in the tensile strength and the modulus of elasticity for the samples treated at high temperatures is due to the improvement in the physical touching between layers. In other words, the high temperature helps in remelting the outer surface of the filament (Figure 12), and as a result, the contact surfaces between filaments become more adhesive with each other. It is clear from the schematic that the contacting surface or the width of bonding of the filaments remelts during the heat treatment process. However, the complete merge between filaments appeared at $150{ }^{\circ} \mathrm{C}$ due to complete fusion in the filament interlayer. Another possible explanation for the increased tensile strength is that the crack must transfer along the sample width as well as perpendicular to filament layers. 
In other words, the amount of impact resistance of 3D-printed polymer composite depends on properties of the material and the interfacial bonding between each layer [36].

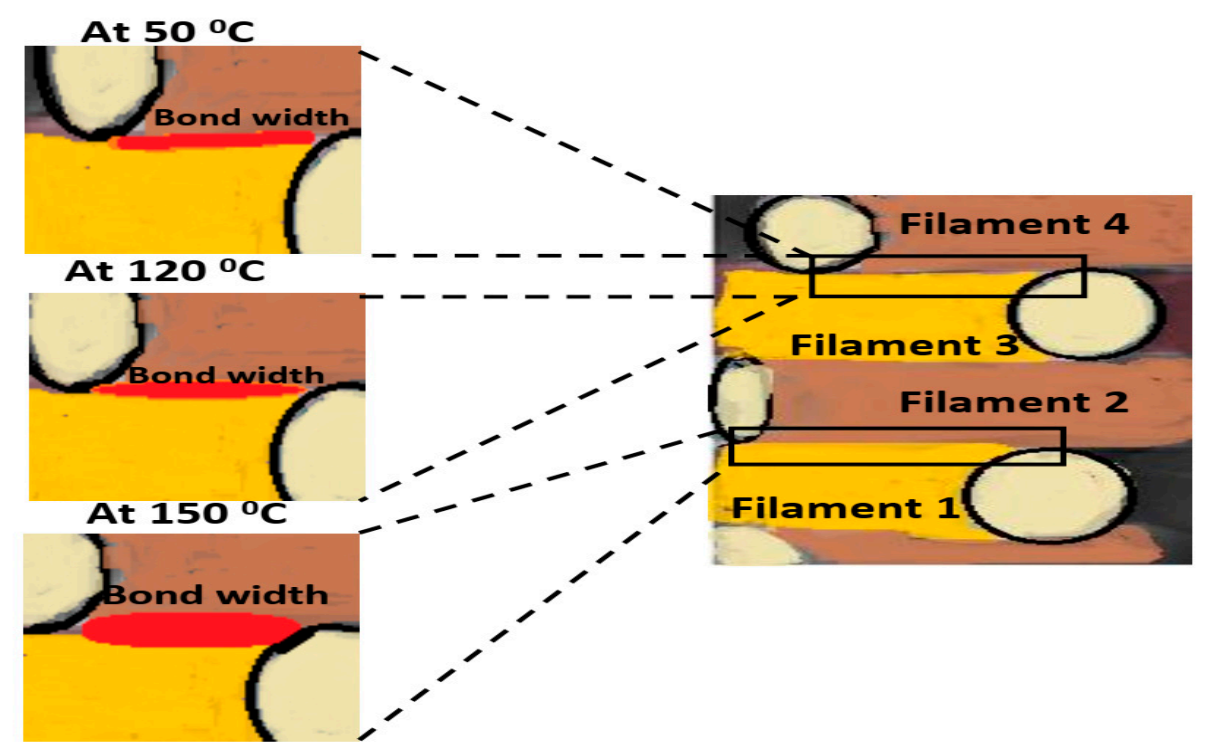

Figure 12. Effect of heat treatment temperature on the contacting surface of the filaments.

In that case, the fracture area will increase which leads to an increase in the sample toughening, and thus the crack took a long time to travel. The combination between two types of filaments shows excellent tensile properties in the case of using two layers of PLACF in the upper and lower layers, and using one layer of ABSCF in the middle of the sample. This is due to PLACF having higher strength than ABSCF. The differences in obtained tensile strength with the changes in heat treatment temperatures may be due to the following reasons:

1. At low temperature $\left(50^{\circ} \mathrm{C}\right)$, only the outer surfaces of the samples were affected by heat treatment; thus, the melting material appeared there (Figure 13a),

2. At high temperatures $\left(120\right.$ and $\left.150{ }^{\circ} \mathrm{C}\right)$, the polymer reaches its melting point temperature; thus, the melting material appeared all over the sample (Figure 13b).

(a) At low temperature

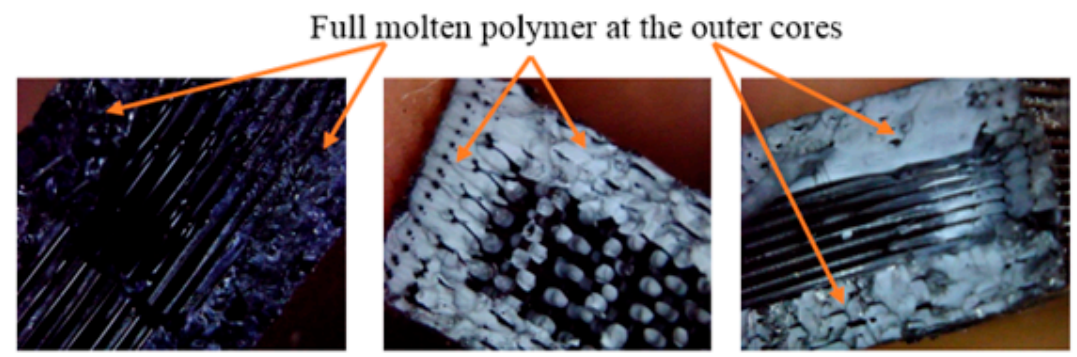

(b) At high temperatures

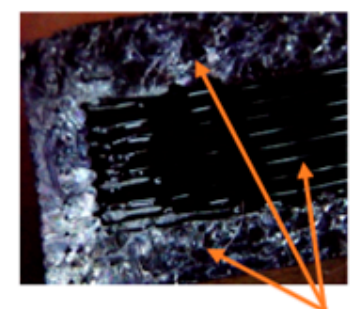

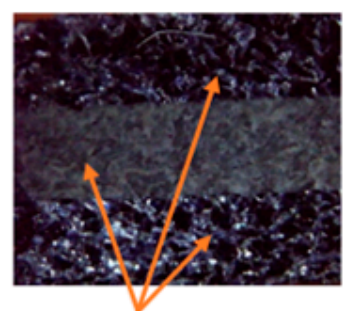

Full molten polymer in inner and outer cores

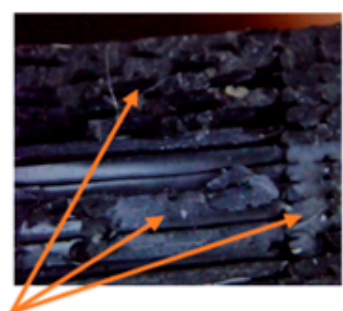

$5 \times$

Figure 13. Effect of heat treatment on the surfaces of different samples, (a) At low temperature $\left(50{ }^{\circ} \mathrm{C}\right),(\mathbf{b})$ At high temperatures $\left(120,150{ }^{\circ} \mathrm{C}\right)$. 
The mechanical performance of 3D-printed products depends on the quality of microstructural morphology which is affected by the porosity of the content and distribution of air pores [52]. The interlayer pores are critical to the tensile properties of the 3D-printed sample; if it is subjected to tensile force across the layer containing those inter pores, the sample will break easily [53]. This is due to inter pores acting as defects inside the product under tensile loading [53-56]. Heat treatment is one of the suitable techniques to eliminate this defect; the air voids will fill with molten material under high temperatures during heat treatment (Figure 14). In the current study, three temperatures were used: low, medium, and high. Low temperature succeeds in removing only some of the surface defects, however medium and high temperatures helped in curing internal defects by reducing the random spherical pores and improving the mechanical properties.

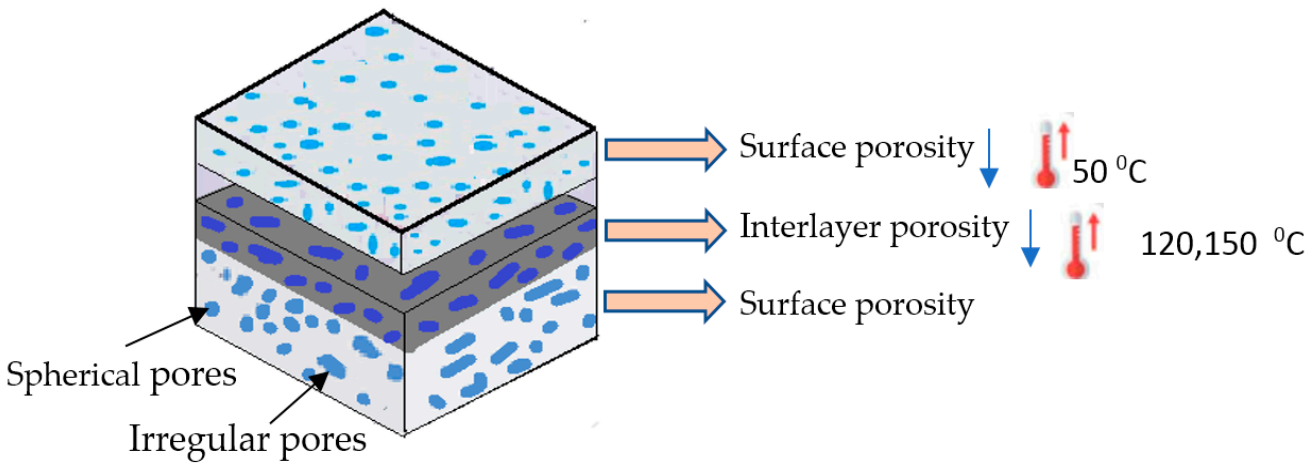

Figure 14. Effect of heat treatment temperature on types and locations of pores.

\section{Conclusions}

In this work, the effects of the heat-treatment process on the physical and mechanical properties of 3D-printed samples using different types of filaments and with different pattern shapes and densities have been examined. Based on the experiments, the following results could be mentioned

- Among the different combinations of input parameters considered for the study, the combination between two types of filaments shows excellent tensile properties in the case of using PLACF as upper and lower layers, and using one layer of ABSCF in the middle,

- Decreasing density of infill up to $70 \%$ leads to increasing increase in the porosity content,

- The best heat-treatment condition for PLACF is $120^{\circ} \mathrm{C}$ and for ABSCF is $150{ }^{\circ} \mathrm{C}$. Under those temperatures, the PLACF and ABSCF filament show maximum tensile strength and low porosity content,

- The maximum tensile strength for heat treatment (at $150{ }^{\circ} \mathrm{C}$ ) samples was $257.4 \mathrm{MPa}$ at sample PLACF/rectilinear pattern and $100 \%$ density,

- There is limited improvement in the tensile strength and modulus of elasticity values for the samples treated at low heat-treatment temperature compared with samples treated at high temperatures,

- At all structure specifications, the rectilinear pattern gives higher strength of up to $33 \%$. This is due to the linear shape of the rectilinear pattern being better than the concentric circular shape of the Archimedean chords pattern,

- Untreated and Archimedean chords pattern exhibited higher porosity \% compared with untreated rectilinear pattern. However, in the case of the heat-treated samples, more interfacial contact and fusion occurs. 
Author Contributions: Conceptualization, A.N., M.Y. and E.N.; methodology, A.N., E.N. and M.Y.; formal analysis, A.N., M.Y., M.E. and E.N.; writing-original draft, A.N., M.Y., M.E. and E.N.; writing-review \& editing, A.N. and E.N. All authors have read and agreed to the published version of the manuscript.

Funding: This research received no specific grant from any funding agency in the public, commercial, or not-for-profit sectors.

Institutional Review Board Statement: Not applicable.

Informed Consent Statement: Not applicable.

Conflicts of Interest: The authors declare no conflict of interest.

\section{Appendix A}
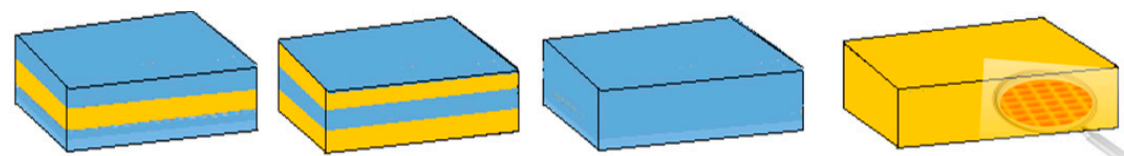

Archimedean chords pattern
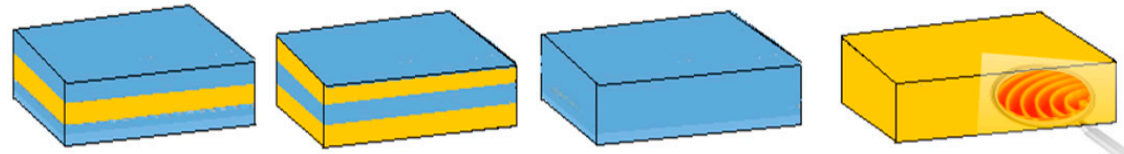

Rectilinear pattern

Figure A1. Layer distribution and infill patterns of the printed specimens.

$\mathbf{T}$

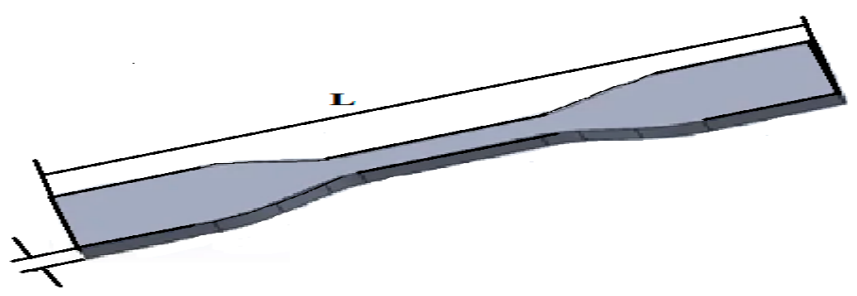

Figure A2. Locations to measure the dimensions of the sample.
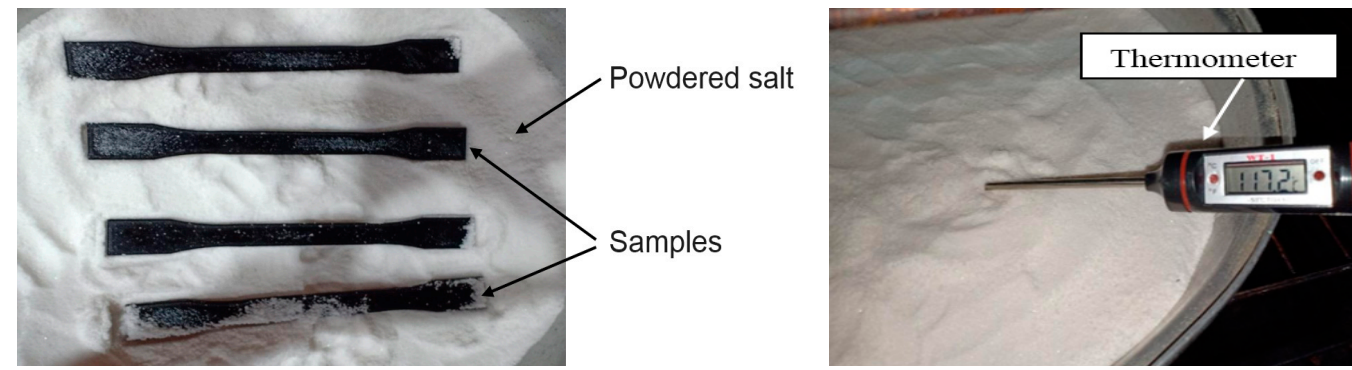

Figure A3. Annealing process. 
Sample code SA11

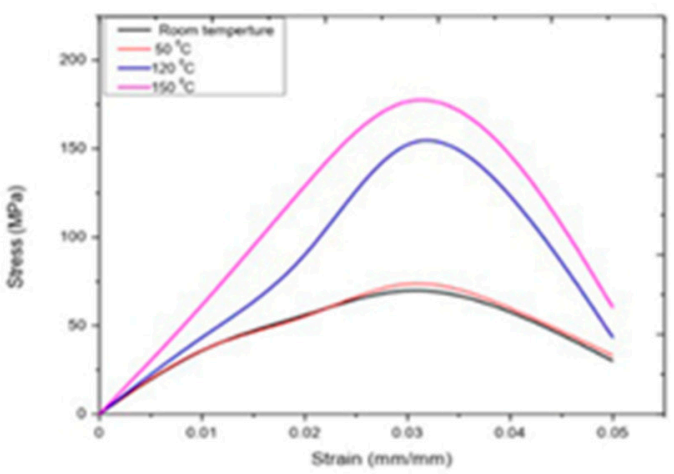

Sample code SA21

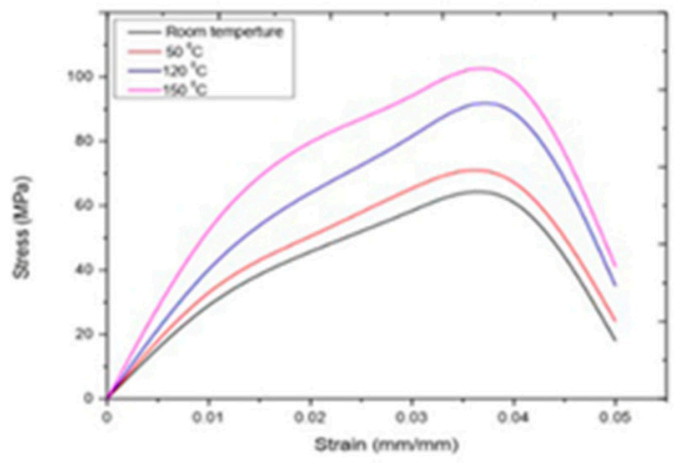

Sample code SP11

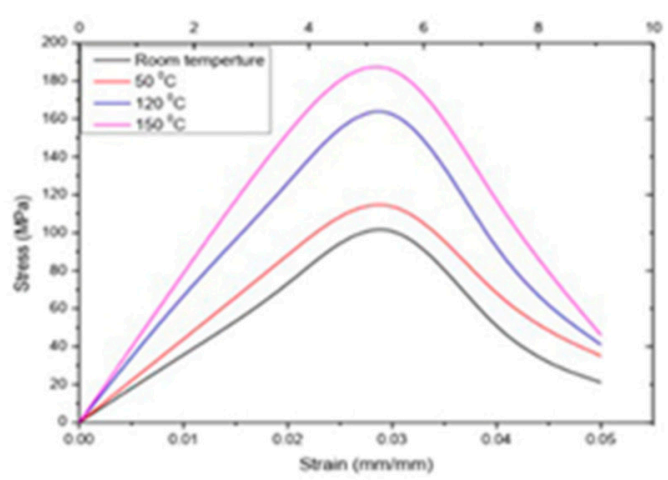

Sample code SP21

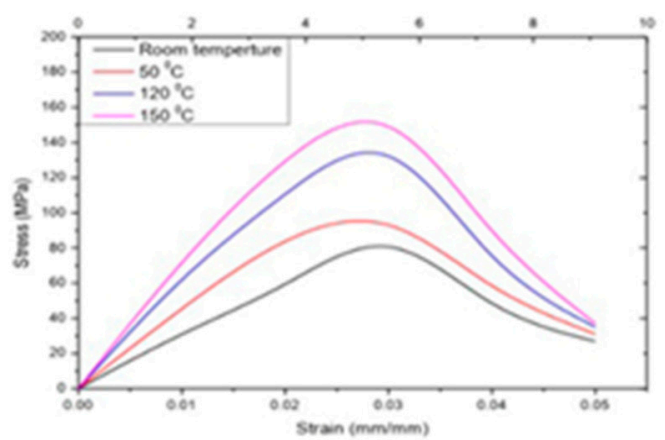

Sample code SA17

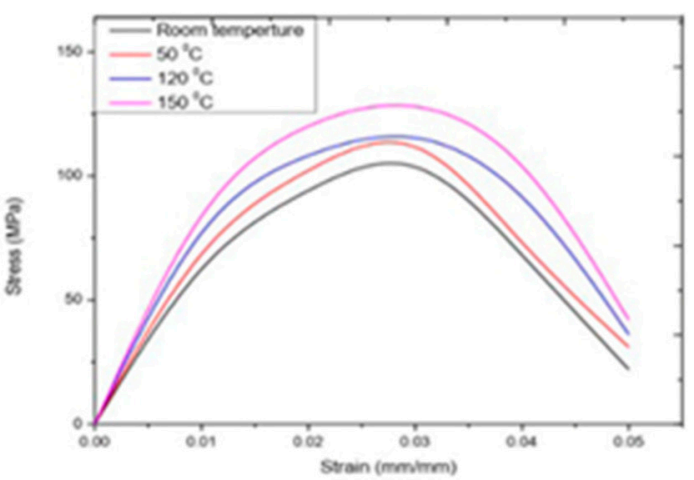

Sample code SA27

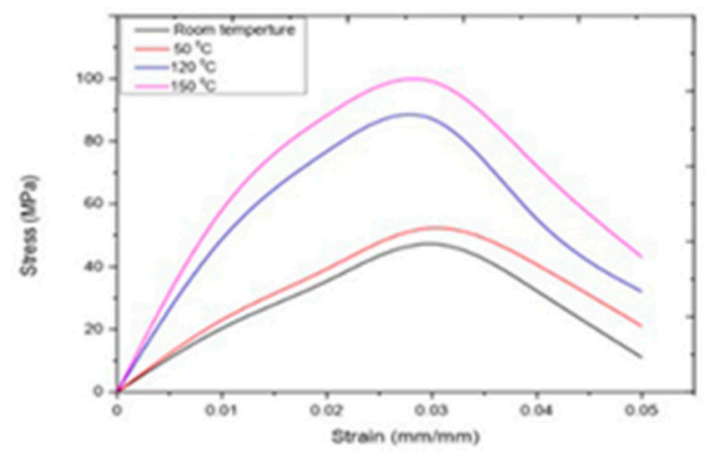

Sample code SP17

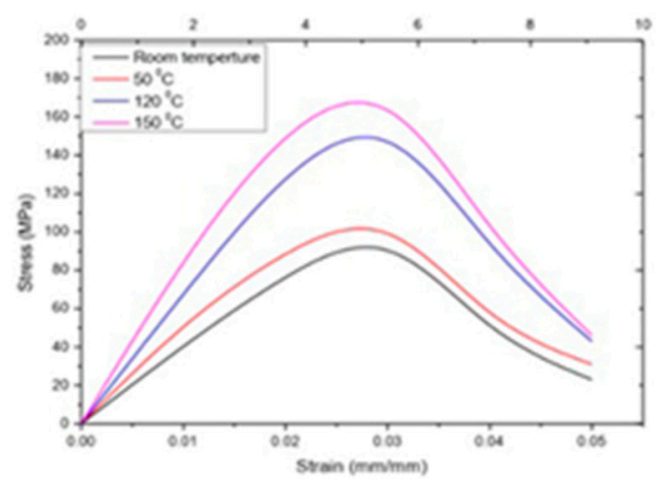

Sample code SP27

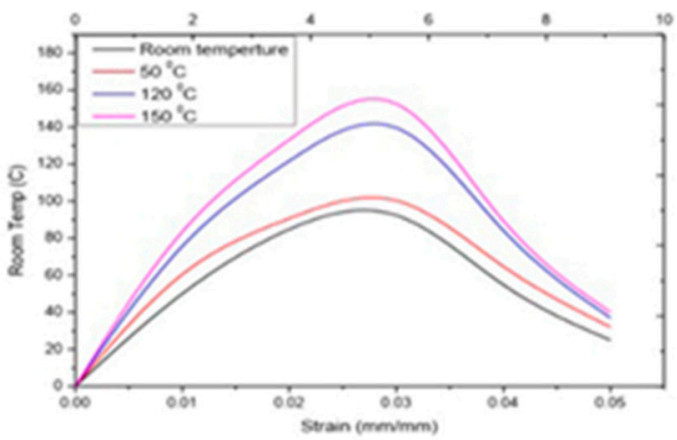

Figure A4. Tensile strength testing results of type A samples. 


\section{Sample code PA11}

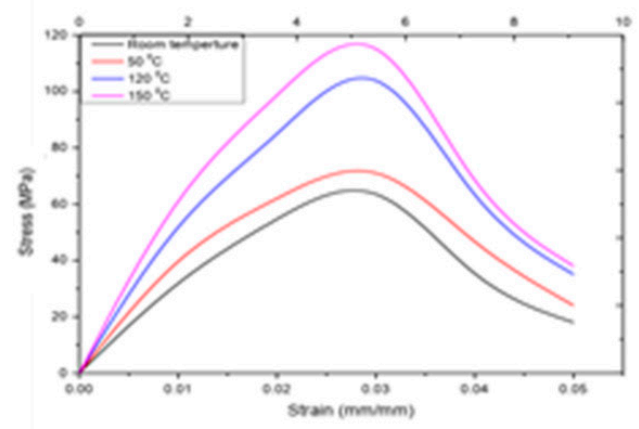

Sample code PA21

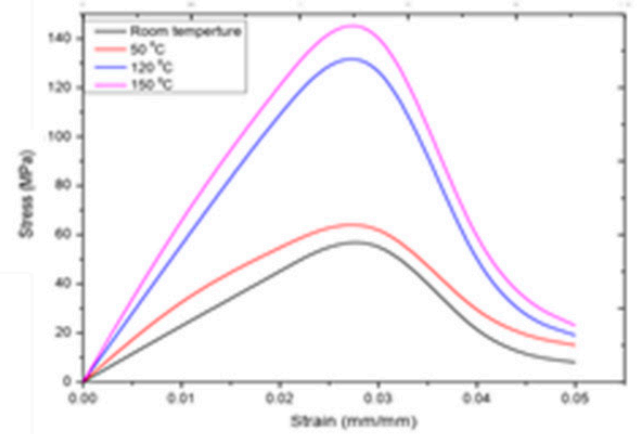

Sample code PP11

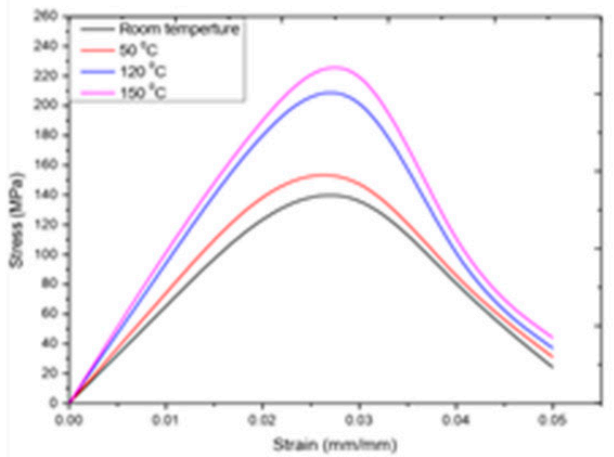

Sample code PP21

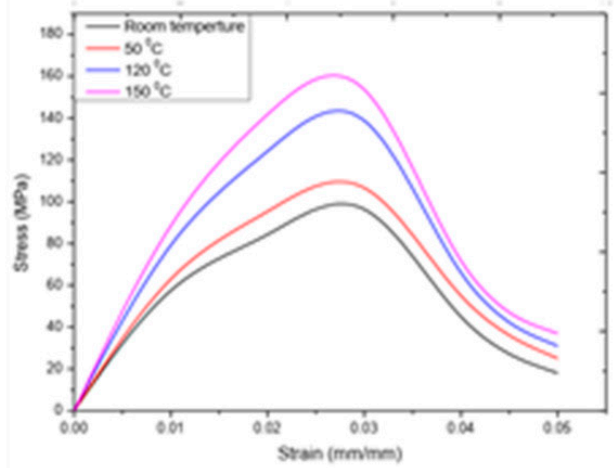

Sample code PA17

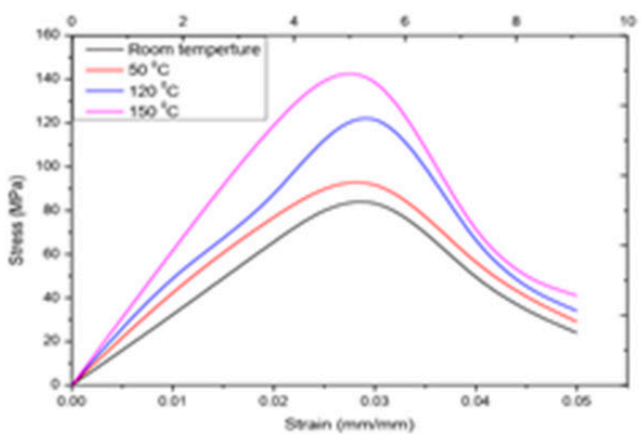

Sample code PA27

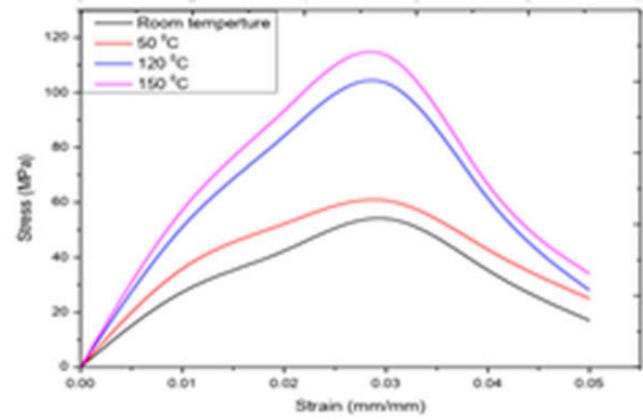

Sample code PP17

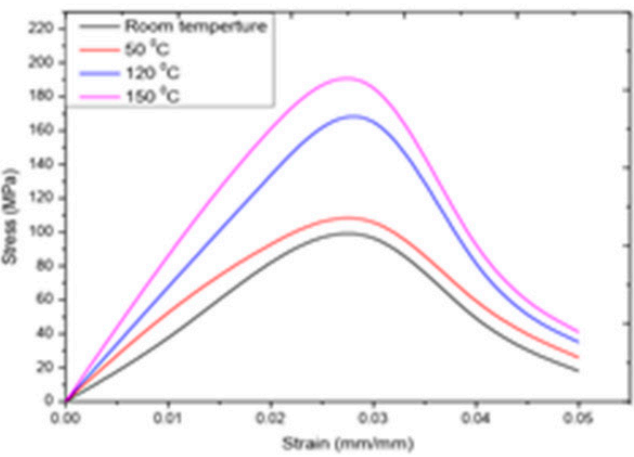

Sample code PP27

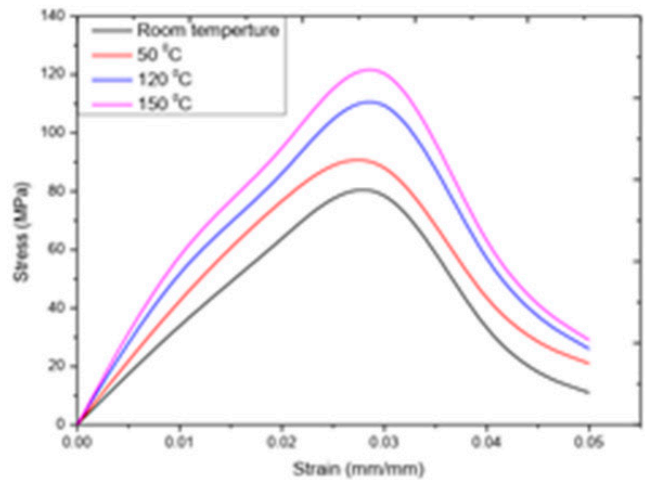

Figure A5. Tensile strength testing results of type B samples. 


\section{References}

1. Snyder, J.; Andrews, M.; Weislogel, M.; Moeck, P.; Stone-Sundberg, J.; Birkes, D.; Hoffert, M.P.; Lindeman, A.; Morrill, J.; Fercak, O.; et al. 3D Systems' Technology Overview and New Applications in Manufacturing, Engineering, Science, and Education. 3D Print. Addit. Manuf. 2014, 1, 169-176. [CrossRef] [PubMed]

2. Goh, G.D.; Yap, Y.L.; Tan, H.K.J.; Sing, S.L.; Goh, G.L.; Yeong, W.Y. Process-structure-properties in polymer additive manufacturing via material extrusion. Crit. Rev. Solid State Mater. Sci. 2019, 45, 113-133. [CrossRef]

3. Shanmugam, V.; Das, O.; Babu, K.; Marimuthu, U.; Veerasimman, A.; Johnson, D.J.; Neisiany, R.E.; Hedenqvist, M.S.; Ramakrishna, S.; Berto, F. Fatigue behaviour of FDM-3D printed polymers, polymeric composites and architected cellular materials. Int. J. Fatigue 2021, 143, 106007. [CrossRef]

4. Gardan, J. Additive manufacturing technologies: State of the art and trends. Int. J. Prod. Res. 2016, 54, 3118-3132. [CrossRef]

5. Wendel, B.; Rietzel, D.; Kühnlein, F.; Feulner, R.; Hülder, G. Additive Processing of Polymers. Macromol. Mater. Eng. 2008, 293, 799-809. [CrossRef]

6. Vaezi, M.; Chianrabutra, S.; Mellor, B.; Yang, S. Multiple material additive manufacturing—Part 1: A review. Virtual Phys. Prototyp. 2013, 8, 19-50. [CrossRef]

7. Khoo, Z.X.; Teoh, J.E.M.; Liu, Y.; Chua, C.K.; Yang, S.; An, J.; Leong, K.F.; Yeong, W.Y. 3D printing of smart materials: A review on recent progresses in 4D printing. Virtual Phys. Prototyp. 2015, 10, 103-122. [CrossRef]

8. Neisiany, R.E.; Khorasani, S.N.; Naeimirad, M.; Lee, J.K.Y.; Ramakrishna, S. Improving mechanical properties of carbon/epoxy composite by incorporating functionalized electrospun polyacrylonitrile nanofibers. Macromol. Mater. Eng. 2017, $302,1600551$. [CrossRef]

9. Shanmugam, V.; Rajendran, D.J.J.; Babu, K.; Rajendran, S.; Veerasimman, A.; Marimuthu, U.; Singh, S.; Das, O.; Neisiany, R.E.; Hedenqvist, M.S.; et al. The mechanical testing and performance analysis of polymer-fibre composites prepared through the additive manufacturing. Polym. Test. 2021, 93, 106925. [CrossRef]

10. Kabir, S.M.F.; Mathur, K.; Seyam, A.F.M. A critical review on 3D printed continuous fibre-reinforced composites: History, mechanism, materials and Properties. Compos. Struct. 2020, 232, 111476. [CrossRef]

11. Alvarez, A.G.; Evans, P.L.; Dovgalski, L.; Goldsmith, I. Design, additive manufacture and clinical application of a patient-specific titanium implant to anatomically reconstruct a large chest wall defect. Rapid Prototyp. J. 2021, 27, 304-310. [CrossRef]

12. Rahim, T.N.A.T.; Abdullah, A.M.; Md Akil, H. Recent Developments in Fused Deposition Modeling-Based 3D Printing of Polymers and Their Composites. Polym. Rev. 2019, 59, 589-624. [CrossRef]

13. Ngo, T.D.; Kashani, A.; Imbalzano, G.; Nguyen, K.T.Q.; Hui, D. Additive manufacturing (3D printing): A review of materials, methods, applications and challenges. Compos. Part B Eng. 2018, 143, 172-196. [CrossRef]

14. Tadesse, M.G.; Dumitrescu, D.; Loghin, C.; Chen, Y.; Wang, L.; Nierstrasz, V. 3D Printing of NinjaFlex Filament onto PEDOT:PSSCoated Textile Fabrics for Electroluminescence Applications. J. Electron. Mater. 2018, 47, 2082-2092. [CrossRef]

15. Nasirov, A.; Fidan, I. Prediction of mechanical properties of fused filament fabricated structures via a symptotic homogenization. Mech. Mater. 2020, 145, 103372. [CrossRef]

16. Khorasani, M.; Ghasemi, A.; Rolfe, B.; Gibson, I. Additive manufacturing a powerful tool for the aerospace industry. Rapid Prototyp. J. 2021. [CrossRef]

17. Wendt, C.; Valerga, A.P.; Droste, O.; Batista, M.; Marcos, M. FEM based evaluation of Fused Layer Modelling monolayers intensile testing. Procedia Manuf. 2017, 13, 916-923. [CrossRef]

18. Ahn, S.; Montero, M.; Odell, D.; Roundy, S.; Wright, P.K. Anisotropic material properties of fused deposition modeling ABS. Rapid Prototyp. J. 2002, 8, 248-257. [CrossRef]

19. Mohan, N.; Senthil, P.; Vinodh, S.; Jayanth, N. A review on composite materials and process parameters optimisation for the fused deposition modelling process. Virtual Phys. Prototyp. 2017, 12, 47-59. [CrossRef]

20. Chacón, J.M.; Caminero, M.A.; García-Plaza, E.; Núñez, P.J. Additive manufacturing of PLA structures using fused deposition modelling: Effect of process parameters on mechanical properties and their optimal selection. Mater. Des. 2017, 124, 143-157. [CrossRef]

21. Cuan-Urquizo, E.; Espinoza-Camacho, J.I.; Álvarez-Trejo, A.; Uribe, E.; Treviño-Quintanilla, C.D.; Crespo-Sánchez, S.E.; GómezEspinosa, A.; Roman-Flores, A.; Olvera-Silva, O. Elastic response of lattice arc structures fabricated using curved-layered fused deposition modeling. Mech. Adv. Mater. Struct. 2021, 28, 1498-1508. [CrossRef]

22. Ashby, M.F.; Evans, T.; Fleck, N.A.; Hutchinson, J.W.; Wadley, H.N.G.; Gibson, L.J. Metal Foams: A Design Guide, 1st ed.; Elsevier: Amsterdam, The Netherlands, 2000; pp. 113-149.

23. Daniel, I.M.; Abot, J.L. Fabrication, testing and analysis of composite sandwich beams. Compos. Sci. Technol. 2000, 60, 2455-2463. [CrossRef]

24. Herranen, H.; Pabut, O.; Eerme, M.; Majak, J.; Pohlak, M.; Kers, J.; Saarna, M.; Allikas, G.; Aruniit, A. Design and testing of sandwich structures with different core materials. Mater. Sci. 2012, 18, 45-50. [CrossRef]

25. Lanzotti, A.; Grasso, M.; Staiano, G.; Martorelli, M. The impact of process parameters on mechanical properties of parts fabricated in PLA with an open-source 3-D printer. Rapid Prototyp. J. 2015, 21, 604-617. [CrossRef]

26. Kuznetsov, V.E.; Tavitov, A.G.; Urzhumtsev, O.D.; Mikhalin, M.V.; Solonin, A.N. Design and Fabrication of Strong Parts from Poly (Lactic Acid) with a Desktop 3D Printer: A Case with Interrupted Shell. Polymers 2019, 11, 760. [CrossRef] 
27. Wang, X.; Zhao, L.; Fuh, J.Y.H.; Lee, H.P. Effect of porosity on mechanical properties of 3D printed polymers: Experiments and micromechanical modeling based on X-ray computed tomography analysis. Polymers 2019, 11, 1154. [CrossRef]

28. Fernandez-Vicente, M.; Calle, W.; Ferrandiz, S.; Conejero, A. Effect of Infill Parameters on Tensile Mechanical Behavior in Desktop 3D Printing. 3D Print. Addit. Manuf. 2016, 3, 183-192. [CrossRef]

29. Singh, R.; Kumar, R.; Farina, I.; Colangelo, F.; Feo, L.; Fraternali, F. Multi-Material Additive Manufacturing of Sustainable Innovative Materials and Structures. Polymers 2019, 11, 62. [CrossRef]

30. Kumar, R.; Singh, R.; Farina, I. On the 3D printing of recycled ABS, PLA and HIPS thermoplastics for structural applications. PSU Res. Rev. 2018, 2, 115-137. [CrossRef]

31. Najim, A.; Saad, A.S. An Investigation of New Design of Light Weight Structure of (ABS/PLA) by Using of Three Dimensions Printing. In Proceedings of the 13th International Conference "Standardization, Protypes and Quality: A Means of Balkan Countries' Collaboration", Brașov, Romania, 3-4 November 2016; pp. 482-487.

32. Brischetto, S.; Ferro, C.G.; Torre, R.; Maggiore, P. 3D FDM production and mechanical behavior of polymeric sandwich specimens embedding classical and honeycomb cores. Curved Layer. Struct. 2018, 5, 80-94. [CrossRef]

33. Santosh, R.V.N.; Sarojini, J.; Vikram, K.A.; Lakshmi, V.V.K. Evaluating the Mechanical Commonly Used 3D Printed Polymers with Properties of ABS Multi Layered and PLA Polymers. Int. J. Eng. Adv. Technol. 2019, 8, 2351-2356.

34. Pradeep, K.M.; Senthil, P.; Mohan, N. The influence of process parameters on the impact resistance of 3D printed PLA specimens under water-absorption and heat-treated conditions. Rapid Prototyp. J. 2021, 27, 1327-1336. [CrossRef]

35. Zhang, T.; Wang, N.-N.; Lu, Z.-L.; Jing, X.-Y.; Hu, C.-J. Diagnostic performance of magnetic beads-based matrix-assisted laser desorption/ionization time-of-flight mass spectrometry for esophageal squamous cell carcinoma: A meta-analysis. Front. Lab. Med. 2018, 2, 55-62. [CrossRef]

36. Basgul, C.; Yu, T.; MacDonald, D.W.; Siskey, R.; Marcolongo, M.; Kurtz, S.M. Does annealing improve the interlayer adhesion and structural integrity of FFF 3D printed PEEK lumbar spinal cages? J. Mech. Behav. Biomed. Mater. 2020, 102, 103455. [CrossRef] [PubMed]

37. Akhoundi, B.; Nabipour, M.; Hajami, F.; Shakoori, D. An Experimental Study of Nozzle Temperature and Heat Treatment (Annealing) Effects on Mechanical Properties of High-Temperature Polylactic Acid in Fused Deposition Modeling. Polym. Eng. Sci. 2020, 60, 979-987. [CrossRef]

38. Wang, J.; Xie, H.; Weng, Z.; Senthil, T.; Wu, L. A novel approach to improve mechanical properties of parts fabricated by fused deposition modeling. Mater. Des. J. 2016, 105, 152-159. [CrossRef]

39. Von Windheim, N.; Collinson, D.W.; Lau, T.; Brinson, L.C.; Gall, K. The influence of porosity, crystallinity and interlayer adhesion on the tensile strength of 3D printed polylactic acid (PLA). Rapid Prototyp. J. 2021, 27, 1327-1336. [CrossRef]

40. Travieso-Rodriguez, J.A.; Jerez-Mesa, R.; Llumà, J.; Gomez-Gras, G.; Casadesus, O. Comparative study of the flexural properties of ABS, PLA and a PLA-wood composite manufactured through fused filament fabrication. Rapid Prototyp. J. 2021, $27,81-92$. [CrossRef]

41. Afonso, J.A.; Alves, J.L.; Caldas, G.; Gouveia, B.P.; Santana, L.; Belinha, J. Influence of 3D printing process parameters on the mechanical properties and mass of PLA parts and predictive models. Rapid Prototyp. J. 2021, 27, 487-495. [CrossRef]

42. Bhandari, S.; Lopez-Anido, R.A.; Gardner, D.J. Enhancing the interlayer tensile strength of 3D printed short carbon fiber reinforced PETG and PLA composites via annealing. Addit. Manuf. 2019, 30, 100922. [CrossRef]

43. Calignano, F.; Lorusso, M.; Roppolo, I.; Minetola, P. Investigation of the Mechanical Properties of a Carbon Fibre-Reinforced Nylon Filament for 3D Printing. Machines 2020, 8, 52. [CrossRef]

44. Maqsood, N.; Rimašauskas, M. Characterization of carbon fiber reinforced PLA composites manufactured by fused deposition modeling. Compos. Part C Open Access 2021, 4, 100112. Available online: https://www.sciencedirect.com/science/article/pii/S2 666682021000074 (accessed on 4 November 2021). [CrossRef]

45. Pandelidi, C.; Maconachie, T.; Bateman, S.; Kelbassa, I.; Piegert, S.; Leary, M.; Brandt, M. Parametric study on tensile and flexural properties of ULTEM 1010 specimens fabricated via FDM. Rapid Prototyp. J. 2020, 27, 429-451. [CrossRef]

46. Anderson, E.H. The Effect of Porosity on Mechanical Properties of Fused Deposition Manufactured Polymers and Composites. Ph.D. Thesis, San José State University, San Jose, CA, USA, 2019.

47. Keleş, Ö.; Anderson, E.H.; Huynh, J.; Gelb, J.; Freund, J.; Karakoç, A. A Stochastic fracture of additively manufactured porous composites. Sci. Rep. 2018, 8, 15437. [CrossRef]

48. Al-Maharma, A.Y.; Patil, S.P.; Markert, B. Effects of porosity on the mechanical properties of additively manufactured components: A critical review. Mater. Res. Express 2020, 7, 122001. [CrossRef]

49. Mulle, M.; Wafai, H.; Yudhanto, A.; Lubineau, G.; Yaldiz, R.; Schijve, W.; Verghese, N. Influence of process-induced shrinkage and annealing on the thermomechanical behavior of glass fiber-reinforced polypropylene. Compos. Sci. Technol. 2019, 170, 183-189. [CrossRef]

50. Hart, K.R.; Dunn, R.M.; Wetzel, E.D. Increased fracture toughness of additively manufactured semi-crystalline thermoplastics via thermal annealing. Polymer 2020, 211, 123091. [CrossRef]

51. Hart, K.R.; Dunn, R.M.; Sietins, J.M.; Mock, C.M.H.; Mackay, M.E.; Wetzel, E.D. Increased fracture toughness of additively manufactured amorphous thermoplastics via thermal annealing. Polymer 2018, 144, 192-204. [CrossRef]

52. Lv, T.; Zhou, C.; Li, J.; Huang, S.; Wen, H.; Meng, Y.; Jiang, S. New insight into the mechanism of enhanced crystallization of PLA in PLLA/PDLA mixture. J. Appl. Polym. Sci. 2018, 135, 45663. [CrossRef] 
53. Liao, Y.; Liu, C.; Coppola, B.; Barra, G.; Di Maio, L.; Incarnato, L.; Lafdi, K. Effect of Porosity and Crystallinity on 3D Printed PLA Properties. Polymers 2019, 11, 1487. [CrossRef] [PubMed]

54. Bandyopadhyay, A.; Heer, B. Additive manufacturing of multi-material structures. Mater. Sci. Eng. R Rep. 2018, 129, 1-16. [CrossRef]

55. Hofstätter, T.; Pedersen, D.B.; Tosello, G.; Hansen, H.N. State-of-the-art of fiber-reinforced polymers in additive manufacturing technologies. J. Reinf. Plast. Compos. 2017, 36, 1061-1073. [CrossRef]

56. Mohammadizadeh, M.; Fidan, I. Tensile Performance of 3D-Printed Continuous Fiber-Reinforced Nylon Composites. J. Manuf. Mater. Process. 2021, 5, 68. [CrossRef] 